\title{
New craniodental remains of Thylacinus potens (Dasyuromorphia: Thylacinidae), a carnivorous marsupial from the late Miocene Alcoota Local Fauna of central Australia
}

New craniodental specimens that are referrable to the thylacinid marsupial, Thylacinus potens, are described from the late Miocene Alcoota Local Fauna of the Northern Territory, Australia. The remains include a largely complete maxilla and dentary, showing for the first time the anterior dentition of the dentary. The new remains indicate that Th. potens was a more variable species than previously recognised. The dentary, in particular, is more gracile, than other specimens referred to this species. A revised apomorphy-based diagnosis of $T h$. potens that takes this variability into account is presented. A cladisitic analysis supports previous analyses that placed Th. potens in a derived position within Thylacinidae, close to the modern Th. cynocephalus. New estimations of body size are made using published regressions of dental measurements of dasyuromorphians as well as by assuming geometric similitude with Th. cynocephalus. All methods produce body mass estimates in excess of 35 $\mathrm{kg}$. 
1 Adam M. Yates

2 Museums and Art Galleries of the Northern Territory

3 Museum of Central Australia, P.O. Box 831, Alice Springs, Northern Territory, 0871

4 Australia

5 Corresponding author: Adam M. Yates, Museum of Central Australia, P.O. Box 831, Alice

6 Springs, Northern Territory, 0871, Australia, ph. +61 (08) 89511148, email:

7 adamm.yates@nt.gov.au 


\section{Introduction}

9 The recently extinct 'Tasmanian tiger' (Thylacinus cynocephalus) was Australia's largest

10 surviving mammalian carnivore at the time of European settlement. It belongs to a family of

11 marsupial carnivores, the Thylacinidae, whose fossil record extends back to the late Oligocene

12 (approximately $24 \mathrm{ma}$ ) (Wroe, 2003). Molecular phylogenetics based on surviving Th.

13 cynocephalus tissues have revealed conclusively that the Thylacinidae was part of

14 Dasyuromorphia, a clade of australodelphian marsupials that include the surviving Australo-

15 Papuan marsupial carnivores, the Dasyuridae, and the numbat (Myrmecobius fasciatus), an ant-

16 eating specialist (Krajewski, Buckley \& Westerman, 1997; Beck, 2008; Miller et al., 2009).

17 Many thylacinids had body sizes equal to, or larger than the largest dasyurids, although there is

18 substantial overlap in body size between the two families (Wroe, 2001). The very largest

19 thylacinids belong to the derived genus Thylacinus and one of the largest known species of this

20 genus is the late Miocene Th. potens Woodburne, 1967 from the Alcoota Local Fauna, possibly

21 reaching a bodyweight close to $40 \mathrm{~kg}$ (Wroe, 2001). Th. potens lived at an important time in the

22 history of thylacinids, when the great diversity of late Oligocene and early-middle Miocene

23 small-bodied thylacinids were becoming extinct and Thylacinus species were evolving larger

24 size, presumably as a specialisation towards predation on large-bodied vertebrate prey.

25 Unfortunately our anatomical and palaeobiological knowledge of Th. potens remains poor due to

26 its frustratingly meagre fossil record. The original hypodigm of Th. potens consisted of the

27 holotype palate, two dentary fragments, some teeth and a few postcranial elements from the hind

28 foot (Woodburne, 1967). Since that time, scant material has been added, despite extensive annual

29 excavations at Alcoota carried out over a 27 year period by a joint team from Flinders University

30 (FU) and the Museum and Art Gallery of the Northern Territory (MAGNT). However, the 2013

31 expedition saw the discovery of the first substantial craniodental remains of this species to be

32 recovered since Woodburne's initial excavation of the Alcoota local fauna in 1962-63.

33 These new specimens expand our knowledge of the anatomy of this species and its range of

34 variation. As a result of this new information the diagnosis of the species is revised. With more

35 complete specimens at hand, new estimates of the size of Th. potens are also calculated.

\section{Geological Setting}

37 The Alcoota Local Fauna is known from a dense bone bed in the lower part of the Waite

38 Formation, cropping out on Alcoota Station, $110 \mathrm{~km} \mathrm{NE}$ of Alice Springs in south central

39 Northern Territory (Woodburne, 1967). The Waite Formation is a late Cenozoic sequence of

40 fluviatile silts, sands and minor limestone beds filling the Waite Basin, a small intermontane

41 basin, surrounded by crystalline rocks of the Arunta Block (Woodburne, 1967). The bone bed

42 covers an area of approximately $25000 \mathrm{~m}^{2}$, although its density and thickness varies considerably

43 within that area (Megirian, 2000). The bonebed usually lies $90 \mathrm{~cm}$ below the present soil surface, 
44 underneath a reddish, weathered horizon (Murray \& Megirian, 1992). The bulk of the known

45 fossil material has been obtained from three pits: Paine Quarry, South Pit and Main Pit. Paine

46 Quarry was excavated by Woodburne and colleagues from 1962 to 1963, and produced the

47 original Th. potens material that was described by Woodburne (1967) when he erected the

48 species. The pit was presumably backfilled at the end of Woodburne's field investigations in

49 1963. South Pit and Main Pit were opened by a team from FU and MAGNT in the mid 1980's

50 and have been kept open and have been more or less continually excavated up to the present. The

51 precise location of Paine Quarry in relation to the FU-MAGNT pits has always been uncertain

52 but recent work matching old, long-lived trees to those present in Woodburne's original field

53 photographs indicates that it lay immediately west of the present day South Pit (Fig. 1).

54 Based on stage of evolution correlation it is thought that the fauna is late Miocene in age (Stirton,

55 Woodburne \& Plane, 1967; Murray \& Megirian, 1992), and lies somewhere between 5 and 12

56 million years old (Megirian et al., 2010). The fauna is dominated by large browsing herbivores,

57 both mammalian and avian. Mammalian carnivores are exceptionally rare and restricted to just

58 three known species: Th. potens, Tyarrpecinus rothi and Wakaleo alcootaensis (Woodburne,

59 1967; Murray \& Megirian, 2000; Archer \& Rich, 1982). Of these, Ty. rothi is a small thylacinid,

60 weighing about $5 \mathrm{~kg}$ (Wroe, 2001) that is known only from a single fragmentary specimen

61 (Murray \& Megirian, 2000).W. alcootaensis is a leopard-sized thylacoleonid weighing about

$6235 \mathrm{~kg}$ that is known from even less material than Th. potens. Apart from the specimens of Th.

63 potens described by Woodburne (1967), FU-MAGNT excavations in Main Pit have produced a

64 few postcranial elements, a canine crown, a largely uninformative molar fragment and a single

65 heavily worn and broken molar.

66 During the 2013 field season a new pit was opened between the Main Pit and South Pit, at the 67 same stratigraphic height as these two quarries (Fig. 1). This new pit, named 'Shattered Dreams',

68 proved to be exceptionally densely packed with fragmented bones, interspersed with occasional

69 complete, or near complete specimens. Not only was the volume of fossil bone extraordinarily

70 high but the diversity was also high with almost all of the known taxa from the Alcoota Local

71 Fauna recovered from an excavated area of less than two square meters. Among these specimens

72 are postcranial elements as well as upper and lower jaw bones bearing teeth that are referrable to

73 Th. potens. In addition an isolated premolar was discovered in South Pit. These are the first

74 substantial craniodental remains of this species to be recovered since Woodburne's initial

75 excavation of the Alcoota local fauna.

\section{Methods}

\section{Terminology}

78 Serial designation of the cheek dentition follows Flower (1867) and Luckett (1993). Standard

79 nomenclature for mammalian tooth cusp anatomy is followed. Anterior and posterior are used as

80 anatomical directions in the description of the dentition (replacing mesial and distal,

81 respectively). This is done to bring the description into line with the rest of the descriptive

82 literature on thylacinids. As the jaws of thylacinids are elongate and the dental arcades are rather 
83 straight and anteroposteriorly oriented, anterior and posterior are synonymous with the dental

84 directional terms mesial (toward the symphysis) and distal (away from the symphysis), at least

85 for the canine and post canine dentition.

86 Institutional Abbreviations are as follows: CPC, Commonwealth Palaeontological Collection, 87 Geoscience Australia, Canberra; NTM, Museum and Art Gallery of the Northern Territory, 88 Darwin and Alice Springs; SAM, South Australian Museum, Adelaide; UCMP, Museum of 89 Paleontology, University of California, Berkeley.

\section{$90 \quad$ Size Estimation}

91 Two methods were used to calculate the body mass of the new Th. potens specimens: NTM 92 P4326 and NTM P4327. Firstly, some of Myers' (2001) regressions were selected. These

93 regressions were derived to predict body mass of marsupials from a series of craniodental

94 measurements. Three such regressions were used, all derived from the restricted

95 dasyuromorphian dataset (Myers, 2001, table 4). The regression for lower molar tooth row was

96 used to estimate the mass of the dentary specimen (NTM P4327) while the regressions for upper

97 molar tooth row length and width of $\mathrm{M}^{2}$ was used for the maxilla specimen (NTM P4326).

98 Unfortunately $\mathrm{M}^{1}$ of NTM P4326 is badly damaged and isolated from the rest of the molar row.

99 Consequently the length of the upper molar tooth row could only be estimated, hence the use of

100 the second, less accurate predictive variable. Myers (2001) applied a smearing estimate (Duan,

101 1983) to his predicted body mass values to correct for logarithmic transformation bias that results

102 when the predicted value is detransformed. The same smearing estimates are applied here.

103 The second method used to estimate body mass follows that of Wroe (2001), who assumed

104 geometric similitude between large-bodied species of Thylacinus and obtained a scaling factor by

105 comparing measurements of the fossils with the average of the same measurement from $T h$.

106 cynocephalus. In this study the measurements used to obtain the scaling factors were lower molar 107 tooth row length for the dentary specimen (NTM P4327) and the combined length of $\mathrm{M}^{2-4}$ for the 108 maxilla specimen (NTM P4326). Average values for Th. cynocephalus were obtained from Wroe 109 (2001, table 4) and Woodburne (1967, table 1). An average mass of $29.5 \mathrm{~kg}$ for Th. cynocephalus 110 (Paddle 2000) was used to scale body mass.

\section{Cladistic Analysis}

112 Several cladistic analyses of thylacinid and dasyuromorphian phylogeny have been attempted.

113 However, no published character-taxon matrix includes all available informative characters and

114 all thylacinid taxa described to date. Therefore a new matrix was assembled by combining data 115 from previous analyses with the addition of some new character scores for Th. potens and Th.

116 megiriani. The ingroup was restricted to Thylacinidae and characters that were uninformative

117 within the restricted ingroup were excluded. Two dasyurids (Barinya wangala and Antechinus

118 flavipes) were employed as outgroup taxa. New character states for Th. potens were taken from

119 the specimens described in this article while new character states for Th. megiriani were taken

120 from undescribed lower jaw specimens held in the NTM collections (NTM P4376, 4377).

121 Polymorphisms were treated as uncertainty. Terminal taxa used and their sources of character 
122 data are given in Table 1. Body mass was employed as an ordered multistate character. This is not

123 a common practice because there is a belief that bodysize is too plastic to be usefull for cladistics

124 analysis, andthat such phenomena as sexual dimorphism would confound its use. However the

125 same could be said of a great many characters routinely employed in cladistics analysis. Body

126 size is included here because it does display a high degree of heritability and therefore contains

127 phylogenetic signal and its exclusion would violate the principal of total evidence. Furthermore

128 body size is one of relatively few characteristics that varies between the larger derived species of

129 Thylacinus. Specifically the exceptional size of both Th. potens and Th. megiriani is a potential

130 synapomorphy linking these two species as sister taxa. Such an arrangement has significant

131 impacts for the reconstruction of thylacinid evolution in the late Cenozoic and deserves to be

132 tested as thoroughly as possible. Characters (Appendix 1) were taken from Murray (1997),

133 Muirhead \& Wroe (1998), Wroe \& Musser (2001), Murray \& Megirian (2006) with some

134 modification. A few novel characters were added.

135 The resulting matrix was subjected to a maximum parsimony analysis in PAUP 4.0b (Swofford,

136 2001) using the following settings: heuristic search; random addition sequence with 500

137 replicates; and TBR branch-swapping algorithm. The strength of the internal nodes was tested

138 with a bootstrap analysis (1000 bootstrap replicates, heuristic searching with 50 addition

139 sequence replicates).

140 Graphical representation of the common cladistic information of the most parsimonious trees

141 (MPTs) was achieved by a posteriori pruning of labile taxa, i.e. a reduced cladistic consensus tree

142 (Wilkinson 1994) was produced. Due to the small number of MPTs, this was achievable by visual

143 inspection of the most parsimonious trees which revealed that all of the loss of resolution in the

144 strict consensus tree was caused by the variable position of a single taxon, Maximucinus

145 muirheadae. This was then pruned from the MPTs, to produce the reduced cladistics consensus

146 tree.

\section{Photography}

148 Monochrome images were prepared by coating the specimens in ammonium chloride and focus-

149 stacking multiple images taken at different focal depths. The interpretive drawings were made

150 from earlier, lower-quality photographs. As a result the drawings do not precisely match the

151 images presented alongside them, however the discrepancies are quite minor and of no

152 consequence.

\section{Systematic Palaeontology}

154 Dasyuromorphia Gill, 1872

155 Thylacinidae Bonaparte, 1838

156 Thylacinus potens Woodburne, 1967

157 Holotype. CPC 6746, "a palatal fragment with $\mathrm{RM}^{2}-\mathrm{M}^{4}$ and $\mathrm{LP}^{2}-\mathrm{M}^{2}$, preserved. Other teeth are 158 represented by roots and alveoli” (Woodburne 1967, pg. 20). 
160 New material. NTM P4326, right maxilla in 2 parts, with complete $\mathrm{P}^{2-3}, \mathrm{M}^{2-4}$, and fragments of $\mathrm{P}^{1}$ 161 and $\mathrm{M}^{1}$ from Shattered Dreams (Figs. 2-9); NTM P4332, isolated left $\mathrm{P}^{3}$ from South Pit (Fig. 10); 162 NTM P4379, maxillary fragment with broken and worn right $\mathrm{M}^{2}$ from Main Pit (Fig. 11); NTM 163 P4327, left dentary with $\mathrm{P}_{2-3,}, \mathrm{M}_{1-4}$ and root fragments of $\mathrm{P}_{1}$ from Shattered Dreams (Fig. 12-15); 164 NTM P4461, crown of right $C_{1}$ from Main Pit (Fig. 16); NTM P4516, fragment of right upper 165 molar, possibly $\mathrm{M}^{1}$, from an unrecorded site of the Alcoota Local Fauna.

166 Emended diagnosis. Thylacinid distinguished by the following unambiguous autapomorphies: 167 long axis of $\mathrm{P}^{1}$ anterobuccally oriented in adults; anterior width of the first upper molar greater 168 than its anterior-posterior length; reduced palatal fenestrae approximately one third the length of 169 the upper molar tooth row; absence of a diastema between $\mathrm{P}_{1}$ and $\mathrm{P}_{2} ; \mathrm{P}_{2}$ longer than $\mathrm{P}_{3}$ and $\mathrm{M}_{1}$. The 170 following ambiguous synapomorphies serve to distinguish Th. potens from Th. cynocephalus

171 (and most fossil thylacinids): ventrally facing sulcus forming the ventral border of the root of the 172 zygomatic arch on the maxilla; $\mathrm{P}^{2}$ longer than $\mathrm{M}^{1}$.

\section{Description}

\section{Maxilla}

175 The maxilla (NTM P4326) includes the tall side wall of the rostrum that is absent in the holotype.

176 The height of the maxilla above the anterior edge of $\mathrm{P}^{3}$ is $44.4 \mathrm{~mm}$ which is $67.3 \%$ of the distance 177 from the anterior margin of the canine to the posterior margin of $\mathrm{P}^{3}$ or approximately $42 \%$ of the 178 total length of the cheek tooth row. These proportions lie with the range of Th. cynocephalus 179 (Table 2). Furthermore, the anterodorsal margin of the maxilla rises from the level of the canine 180 to the level of $\mathrm{P}^{3}$ at an angle of $32^{\circ}$ (Fig. 4A), which matches the angle seen in Th. cynocephalus. 181 These observations indicate that the snout of Th. potens was probably not proportionately shorter 182 or deeper than that of Th. cynocephalus and that the crowding of the premolar teeth seen in this 183 species is more likely to be the result of relative enlargement of these teeth as opposed to relative 184 shortening of the jaw (Fig. 3). In anterior view the lateral wall of the maxilla slopes 185 dorsomedially, indicating that the rostrum was triangular in cross section.

186 Ventrally the palatal shelf of the maxilla is complete between the canine and $\mathrm{P}^{2}$. It indicates that 187 the anterior palate in this region was flat and narrow and was located just a couple of millimetres 188 above the lingual alveolar margins. Doubling the distance from the lingual side of the posterior 189 root of $\mathrm{P}^{1}$ to the midline symphysis indicates that the total width of the palate between the 190 posterior roots of $\mathrm{P}^{1}$ is $19.2 \mathrm{~mm}$, distance almost identical to that of the holotype specimen. This 191 is unusually narrow in comparison to Th. cynocephalus, and lies at the small end of the range 192 displayed by that species (Table 2), indicating that Th. potens may have had a relatively narrow 193 anterior end of the snout (Fig. 2C). A small notch at the anterior end of the preserved portion of 194 the palate is the posterior end of the incisive foramen. It indicates that in this specimen the 195 posterior terminations of these foramina lay between the anterior ends of the canine alveoli, well 196 anterior their position in Th. cynocephalus where they terminate between the canine and P1. The 
197 palate behind the incisive foramen is simple and flat without the depression or low transverse

198 ridge seen in the holotype.

199 The posterior maxillary fragment bears the ventral floor of the infraorbital canal on its dorsal 200 surface (Fig 7C, 8C). From the extent of the broken medial and lateral walls of this canal it is 201 apparent that the lateral opening of this canal, the infraorbital foramen, lay above $\mathrm{M}^{2}$ (Fig. 6B), 202 approximately level with its midlength, as it does in Th. cynocephalus. The lateral margin of the 203 canal dwindles anteriorly to a thin ridge that terminates posterior to the contact between $\mathrm{M}^{1}$ and $204 \mathrm{M}^{2}$, indicating that the infraorbital foramen could not have occupied the anterior position that it 205 does in the holotype of Th. potens. As in the holotype there is a well-developed, ventrally-facing 206 sulcus incised into the posterior lateral surface of the maxilla, forming the ventral margin of the 207 anterior root of the zygomatic arch (7A, D, 8A, D). Also resembling the holotype is a well208 developed pit on the palate between the protocone alveoli of $\mathrm{M}^{3}$ and $\mathrm{M}^{4}$. There is a much 209 shallower and less distinct fossa in the analogous position between $\mathrm{M}^{2}$ and $\mathrm{M}^{3}$. Two short sections 210 of natural edge are present along the largely broken medial margin of the maxillary shelf level 211 with $\mathrm{M}^{1}$ and $\mathrm{M}^{2}$. These represent part of the lateral margin of the palatal vacuity. They indicate 212 that the vacuity lay just $5.8 \mathrm{~mm}$ from the protocone of $\mathrm{M}^{2}$, however there is not enough edge 213 preserved to determine the relative size of the vacuity. Neither is the maxillary shelf complete 214 enough to determine the posterior width of the palate.

\section{Maxillary dentition}

216 The canine alveolus indicates a large, buccolingually compressed and anteriorly directed canine. 217 As in the holotype, the premolars are significantly larger than those of Th. cynocephalus (Table

218 3). The double-rooted $\mathrm{P}^{1}$ is represented by its alveolus and the posterior root bearing a small 219 remnant of the crown. Although none of the crown morphology can be determined it is apparent

220 from the alveolus that the long axis of the tooth in occlusal view is canted buccoanteriorly

221 relative to the long axis of the canine and the succeeding premolars (Fig 4B, 5B). The out-turned

222 anterior margin of the $\mathrm{P}^{1}$ alveolus lies buccal to the posterior margin of the canine alveolus. In

223 lateral view the two margins draw level with each other so that there is no diastema between the

224 two teeth.

225 A short diastema of $3.0 \mathrm{~mm}$ separates $\mathrm{P}^{1}$ from $\mathrm{P}^{2} . \mathrm{P}^{2}$, like the other premolars, is a

226 anteroposteriorly elongate and buccolingually compressed, double-rooted tooth. It is worn to such

227 a degree that the crown is reduced to a low, bluntly rounded, mound-like structure with no

228 discernable cusps. The long axis of the crown in occlusal view is aligned with that of $\mathrm{P}^{3}$. The

229 tooth is distinctly wider at its posterior end than at its anterior end. Although the crowns of $\mathrm{P}^{2}$ and

$230 \mathrm{P}^{3}$ do not contact each other their respective alveoli are in contact and there is no diastema

231 between them (Fig. 4B, 5B).

$232 \mathrm{P}^{3}$ is also heavily worn although the large central protocone remains discernable and distinct from 233 the posterior heel of the crown. NTM P4332 is an isolated $\mathrm{P}^{3}$ in a less worn state (Fig. 10). It 234 shows that the protocone formed a tall conical spike with its apex directed slightly posteriorly.

235 The protocone has a rounded cross-section with no cristae extending up either the anterior or 
236

237

238

239

240

241

242

243

244

245

246

247 A fragment of $\mathrm{M}^{1}$ was recovered from the gap between the two maxillary fragments of NTM

248 P4326. It includes the protocone and the anterobuccal corner of the tooth and their respective

249

250

251

252

253

254

255

256

257

258

259

260

261

262

263

264

265

266

267

268

269

270

271

272

273

274

275

276

posterior sides. The anterior face of the protocone forms a surface that continues to the base of the crown without any change in slope or development of anterior bulges or cuspules. There is a suggestion of a basal bulge on the anterior side of the $\mathrm{P}^{3}$ of NTM P4326 but this is an artefact produced by a wear facet on the anterior face of the protocone. The anteroventrally sloping anterior profile continues in a straight line onto the upper part of the root before curving posteriorly, creating a distinctly rounded profile in lateral view. The posterior profile of the crown has a distinct basal heel, separated from the posterior margin of the protocone by an inflection. A second rounded posterior cuspule arises from the posterolingual surface of the crown base. This cuspule is positioned basal to the level of the posterior heel. The posterior root extends straight down and is not curved like the anterior root. Due to the breakage of NTM P4332 it is not possible to determine if there was a diastema between $\mathrm{P}^{3}$ and $\mathrm{M}^{1}$. roots. The protocone is set lower than the paracone and stylar cusp B, as it is in the other molars. It is worn flat in anterior view and is rounded in occlusal view. A weakly developed precingulum extends along the anterior margin from the linguoanterior corner of the protocone to stylar cusp B. A distinct flexus in the middle of the anterior margin divides the precingulum into two parts, one bordering the protocone, the other the paracone/stylar cusp B complex. The paracone is a low, rounded tubercle. The lingual side of the paracone is somewhat 'tented' with a rounded ridge sloping down from the apex of the paracone to the valley that divides it from the protocone. The precingulum terminates in a poorly developed stylar cusp B. This cusp is no more than a low rounded bulge situated on the buccoanterior side of the paracone.

$\mathrm{M}^{2}$ is complete although somewhat worn. In occlusal view there is a shallow ectoflexus between stylar cusps B and D, at about $40 \%$ of the length of the buccal margin from the anterior end (Fig. 9 ), unlike the holotype which bears a deep ectoflexus similar to that of $\mathrm{M}^{3}$. The anterior and posterolingual margins bear weakly developed constrictions in occlusal view, between the protocone and the buccal cusps. A narrow, rudimentary precingulum slopes basally from the anterior side of stylar cusp B to a point near the base of the anterior side of the crown, below the paracone. The low talon is broadly U-shaped in occlusal view and bears a slightly raised protocone on its lingual apex. The preprotocrista, if it was ever present, has been obliterated by a large steeply angled wear facet occupying the anterior face of the talon. The weakly developed postprotocrista extends horizontally along the posterolingual margin of the talon, terminating immediately lingual to the minute metaconule. The metaconule forms a barely-raised, narrow, semi-lunate shelf around the lingual base of the metacone. The paracone has been worn flat, though its smaller base indicates that it was almost certainly subordinate to the metacone before wear. No paracristae remain but the premetacrista component of the centrocrista can be seen extending down the anterior side of the metacone to the worn base of the paracone. The metacone is the largest cusp of the tooth, its apex has been worn off forming an oblique posterobuccally facing wear facet. The postmetacrista is more of a sharp edge than a raised crest as it is in $T h$. cynocephalus. It curves downwards and buccoventrally from the distolingual edge of the metacone terminating at the posterobuccal corner of the tooth, the posterior end of the metastylar

PeerJ reviewing PDF | (v2014:03:1793:1:0:NEW 30 Jul 2014) 
277 wing. This corner is flat and there is no trace of a raised metastyle. The buccal margin of the

278 stylar shelf forms a raised crest that is higher than the postmetacrista, consequently the metastylar

279 basin faces lingually as opposed to buccally as it does in Th. cynocephalus. The stylar crest rises

280 as it extends anteriorly from the metastylar corner, ending in a well-developed stylar cusp D,

281 which forms a anteroposteriorly elongate and buccolingually compressed cusp. It lies buccally

282 and slightly posterior to the metacone and is the second tallest cusp of the tooth in its present

283 state of wear. A saddle connects stylar cusp D with the metacone that together with the metacone,

284 separates the anterior end of the metastylar basin from the rest of the crown. The stylar crest is

285 terminated by the ectoflexus, anterior to stylar cusp D with the latter being linked to stylar cusp B

286 by a low, rounded saddle. A very small but deep pit is located immediately lingual to this saddle,

287 between stylar cusp D, the metacone and stylar cusp B.

288 The $\mathrm{M}^{3}$ of NTM P4326 is 2-5\% larger than $\mathrm{M}^{2}$ in all measured dimensions (Table 4), unlike the 289 holotype specimen (Woodburne, 1967). In occlusal view there is a well-developed ectoflexus on 290 the buccal margin between stylar cusps B and D, closer to the midlength of the tooth than in $\mathrm{M}^{2}$. 291 The flexure is more strongly developed than in $\mathrm{M}^{2}$, nonetheless it is not as deep as in the $\mathrm{M}^{3}$ of 292 the holotype or the isolated $\mathrm{M}^{3}$ described by Woodburne (1967). The anterior and posterolingual 293 margins bear weakly developed constrictions between the protocone and the buccal cusps. A 294 weakly distinct precingulum extends from the apex of stylar cusp B to a point at the base of the 295 crown adjacent to the anterior constriction. The talon is narrower and more triangular in occlusal 296 view than in $\mathrm{M}^{2}$. The anterior face of the talon curves smoothly onto the occlusal surface of the 297 talon with no preprotocrista defining its margin. The postprotocrista slopes gently down from the 298 apex of the protocone, along the posterolingual margin of the talon. As it approaches the posterolingual surface of the metacone the crista curves sharply towards the base of the crown and a short groove separates it from the metacone. The slightly raised lingual rim of this groove is probably a vestigial metaconule. A tiny, bump-like, vestigial paraconule is present on the anterior edge of the talon, between the protocone and the base of the paracone. There is a strong size disparity between the paracone and the metacone. In lingual view the paracone is a mere bulge on the side of the tall, pyramidal metacone. Extensive wear has removed the apex and the anterior side of the cusp, obliterating the paracristae. The base of the premetacrista forms a slightly taller, rounded blade, indicating that a carnassial notch was originally present between the postparacrista and the premetacrista.The tall conical metacone dominates the crown. Only a small wear facet is developed at its tip. The premetacrista extends steeply down the anterior face of the metacone, parallel with the anterior-posterior axis of the tooth, indicating that the centrocrista was probably straight when the postparacrista component was present. The metacone is a tall conical cusp that dominates the tooth. Only a small wear facet has developed at the tip of the cusp. The postmetacrista forms a sharp edge that extends down the posterior side of the metacone and then continues posterobuccally as a horizontal edge along the posterior margin of the metastylar wing. This part of the postmetacrista is raised slightly above the level of the buccal rim of the stylar shelf so that the metastylar basin is tilted slightly buccally unlike that of $\mathrm{M}^{2}$. The posterobuccal corner of the crown, where the postmetacrista meets the stylar crest is slightly raised producing a vestigial metastyle. The stylar crest is bowed between the metastyle and stylar cusp D in buccal view. Stylar cusp D is smaller and set lower than it is in $\mathrm{M}^{2}$. The ectoflexus 
319 interrupts the stylar crest with a low rounded saddle joing stlyar cusp D with a anterior stylar

320 crest that rises gently to the low summit of stylar cusp B. As in $\mathrm{M}^{2}$ there is a small pit developed

321 lingual to the ectoflexus, adjacent to the base of the metacone.

$322 \mathrm{M}^{4}$ is complete. As in other dasyuromorphians it is reduced in size relative to the preceding 323 molars and is strongly oriented posterolingually. The metastylar wing is strongly reduced in

324 comparison to those of the preceding molars and there is only one large cusp, the paracone, 325 occupying the central region of the tooth, buccal to the protocone. A short but distinct parastylar 326 crest occupies the anterobuccal corner of the tooth. The posterobuccal margin is evenly concave 327 between the metastyle and the parastylar crest, rather than possessing the distinct ectoflexus seen 328 in the preceding molars. The posterobuccal face of the crown slopes strongly down to this margin 329 from the apex of the paracone and is not offset by a stylar shelf. The anterior margin between the 330 parastylar crest and the paracone is distinctly convex in occlusal view. The steeply sloping 331 buccolingual face curves outward at the base of the crown in this region to form a weakly 332 developed precingulum. Weak inflections in occlusal view separate the reduced, U-shaped 333 protocone from the rest of the tooth. The protocone forms a small pointed tubercle that is set 334 lower than the rest of the tooth. The lingual side of the cusp curves buccally toward the tip so that 335 it is set away from the lingual margin and close to the groove separating the protocone from the 336 lingual base of the paracone. The very short pre- and post- protocristae extend close to vertically 337 down the anterior and posterior edges of the buccal face of the protocone. The paracone is the 338 largest cusp of the tooth and forms a central, pyramidal projection. A near vertically oriented 339 wear facet occupies the anterior side of the tooth between the paracone and the parastylar crest, 340 above the precingulum. Two elongate cristae extend from the paracone. The longest of these is 341 the preparacrista which extends in a straight line buccoanteriorly to the parastylar crest. In 342 posterior view the crista slopes gently down from the paracone. The shorter postparacrista 343 extends posteriorly to the metastyle. In lingual view this crista is slopes downward at a steep 344 angle. The short parastylar crest developed at the buccoanterior corner of the tooth bears two 345 minute cuspules which are presumably the parastyle and stylar cusp B.

\section{Dentary}

347 The dentary specimen (NTM P4327) contains the canine alveolus, roots of $\mathrm{P}_{1}$, damaged and 348 incomplete $\mathrm{P}_{2}, \mathrm{P}_{3}, \mathrm{M}_{1}$ and $\mathrm{M}_{2}$ and complete $\mathrm{M}_{3}$ and $\mathrm{M}_{4}$ (Figs. 12, 13). The anterior tip of the 349 dentary is crushed and the tip carrying the incisors and their alveoli is missing. Posteriorly the 350 dentary has broken off at the level of the anterior rise of the coronoind process. The dentary is 351 relatively slender and transversely compressed, although the latter may have been accentuated by 352 post-mortem compaction. The dentary depth below the posterior root of $\mathrm{M}_{4}$ is $33.2 \mathrm{~mm}$, which 353 lies within the range of Th. cynocephalus (Table 2). The medial symphyseal surface extends 354 posteriorly to a level near the posterior end of $\mathrm{P}_{3}$. In lateral view the anterior tip is acutely pointed 355 and the ventral margin in forms a gentle convex curve along its entire length. The ventral margin 356 between $\mathrm{P}_{2}$ and $\mathrm{M}_{1}$ is expanded laterally forming a low ventrolateral torus (Fig. 13A). The lateral 357 surface is depressed above the thickened ventral margin and bears three mental foramina below $358 \mathrm{P}_{2}, \mathrm{P}_{3}$ and $\mathrm{M}_{2}$ respectively. An anterior mental foramen may be present below $\mathrm{P}_{1}$ but crushing and 359 fragmentation of the dentary surface in this area prevents accurate determination. Posteriorly the 
360 lateral surface of the dentary is excavated by the masseteric fossa. The ventral and anterior

361 margins of the fossa are indistinct but it is bordered anterodorsally by a ridge that continues

362 posterodorsally to form the leading edge of the coronoid process.

\section{Dentary dentition}

364 Although the incisor-bearing area is missing there is very little space between the anterior 365 projection of the symphyseal surface and the broken anteromedial margin of the jaw tip, 366 indicating that the incisors must have been small and crowded. The large canine was placed close

367 to the anterior tip of the dentary and apparently projected anterodorsally. An isolated lower canine 368 (NTM P4461) does not differ from those of Th. cynocephalus (Fig. 16). The cheek teeth were 369 closely spaced with all teeth contacting their adjacent teeth except for a short diastema of $4.6 \mathrm{~mm}$ 370 between $\mathrm{P} 1$ and $\mathrm{P} 2$. As in the upper tooth row of the holotype specimen the long axis of $\mathrm{P}_{1}$ is 371 obliquely oriented in relation to $\mathrm{P}_{2}$ and $\mathrm{P}_{3}$ (fig. 12B, 13B).

372 Only the posterior part of $\mathrm{P}_{2}$ is preserved. It indicates a tall, buccolingually compressed triangular 373 tooth, with a rounded posterior margin that descends to the base of the crown without any 374 expansion to form a posterior heel-like cuspid.

375 The apex of the central protoconid is missing from $\mathrm{P}_{3}$. Nonetheless it is clear that it was similar to $376 \mathrm{P}_{2}$ in both size and shape (Table 5). It differs in being buccolingually thicker, and having a 377 concave posterior margin in lateral view that forms a weakly-developed heel-like posterior 378 cuspid. A slight bulge on the anterior profile of the tooth indicates an incipient paraconid.

379 The central protoconid of $\mathrm{M}_{1}$ is heavily worn but the tooth clearly displays a low rounded 380 paraconid with a worn tip, anterior the base of the protoconid. A weak notch on the lingual side of 381 the tooth separates the two cusps. The buccal surface of the bases of these two crowns forms a 382 continuous surface that faces slightly anteriorly and apically. The anterobuccal margin is slightly 383 thickened to form a vague hint of a cingulid. Posterior to the paraconid is a anteroposteriorly 384 short and buccolingually broad talonid shelf. The talonid is slightly wider than the trigonid (Table 385 6). The posterior and lingual sides of the shelf are close to vertical while the buccal side forms an 386 apicolingually sloping surface. The talonid shelf bears a flattened wear surface on its buccal side 387 that represents a worn hypoconid. A shallow anteroposteriorly oriented groove separates this 388 worn area from a low rounded entoconid developed on the lingual side of the talonid.

389 Most of the crown of $\mathrm{M}_{2}$ is missing with the edges worn and rounded suggesting that this tooth 390 was lost during the life of the animal. The worn talonid is slightly broader buccolinually than the 391 talonid of $\mathrm{M}_{1}$. No other details of this tooth are apparent.

$392 \mathrm{M}_{3}$ is well preserved although the linguoanterior corner of the tooth is missing, preventing 393 determination of the height of the paraconid. A narrow but well-developed buccoanterior cingulid 394 slopes steeply posteroventrally from the anterior base of the paraconid to the base of the crown at 395 the level of the anterior margin of the protoconid. The protoconid forms a tall, narrowly 396 triangular cusp in lateral view. The tip is worn with an anterodorsally facing facet intersects the 397 posterior wear facet producing a short transversely aligned crest at the tip of the protoconid. A 
398

399

400

401

402

403

404

405

406

407

408

409

410

411

412

413

414

415

416

417

418

419

420

421

422

423

424

425

426

427

428

429

430

431

432

433

weakly developed preprotocristid extends down the anterior surface of the protoconid to terminate at the base of the paraconid, on its buccal side. A near vertical, posterobuccally facing wear facet occupies the posterior surface of the protoconid. The postprotocristid forms a slightly raised carina along the lingual margin of this wear facet. The postprotocristid extends from the tip of the protoconid and terminates in the notch between the hypoconid and the protoconid. The talonid is a low, anteroposteriorly short shelf that is slightly wider than the trigonid. It bears two main cuspids: the hypoconid and hypoconulid, with a vestigial trace of the entoconid. The hypoconid is worn flat and its roughly circular base is set lingually from the buccal margin, resulting in a sloping buccal side of the talonid. The basal wear facet of the hypoconid lies abuts the base of the protoconid, with just a narrow notch separating them. Thus the cristid obliqua, which would have formed one half of a carnassial notch, has been obliterated. A postcristid extends a short distance from the lingual side of the hypoconid, along the posterior margin of the talonid shelf to the low, pyramidal hypoconulid. Immediately lingual to the hypoconulid, at the posterolingual corner of the talonid, is a bump-like vestige of the entoconid. The lingual side of the talonid is open and the floor of the talonid basin curves downward onto the lingual side of the shelf here.

$\mathrm{M}_{4}$ is complete and well preserved. Its anterior-posterior length is greater than that of $\mathrm{M}_{3}$ (Table 6). A well-developed, conical paraconid forms the second highest cusp of the tooth. It arises from the linguoanterior corner of the tooth. The buccoanterior surface is coplanar with the anterobuccal surface of the protoconid and is bordered basally by a buccoanterior cingulid, similar to that seen in M3. A sharply incised groove separates the posterobuccal surface of the paraconid from the protoconid. The large protoconid is a tall, conical cusp that forms the highest point of the tooth. In buccal view it relatively taller than in Th. cynocephalus, with a straight as opposed to gently convex anterior margin. The groove separating the protoconid from the paraconid is narrower and far shallower than the prominent carnassial notch present in Th. cynocephalus. A weak preprotocristid extends from the buccal end of this groove to the apex of the protoconid. As in $\mathrm{M}^{3}$ there is a nearly vertical wear facet developed on the posterior surface of the protoconid. A distinct postprotocristid forms the lingual border of this wear facet. It extends steeply down the posterior face of the protoconid and meets the postcristid described below in a small carnassial notch. The area occupied by the talonid is reduced relative to the preceding molars. A single cuspid, apparently the hypoconulid, arises from the posterolingual corner of the talonid. This forms a moderately tall conical process that stands $4.5 \mathrm{~mm}$ above the posterior base of the crown. A short postcristid curves anterobuccally from the hypoconulid to join the posterior base of the protoconid. A small swelling on this cristid, where it meets the base of the protocone may represent a reduced remnant of the hypoconid. The lingual side of the talonid shelf is not bordered by any cristid or cuspid and the floor of the shelf slopes downward at its lingual side.

\section{Discussion}

435 Autapomorphies of Th. potens 
436 Woodburne (1967) provided an extensive list of characters that distinguished Th. potens from Th.

437 cynocephalus. Since that time an extensive range of pre-Pleistocene thylacinids have been

438 discovered. These indicate that many of the diagnostic characters proposed by Woodburne are

439 widely distributed among pre-Pleistocene thylacinids and represent plesiomorphic characters that

440 are general for thylacinids. Other proposed diagnostic characters can now be shown to vary

441 within Th. potens, with the addition of new specimens described above. The following five

442 characters stand as unambiguous autapomorphies of Th. potens:

443 Long axis of $P^{l}$ mesiobuccally oriented in adults (modified from Murray, 1997). In occlusal view the anterior-posterior axis of the first upper premolar is aligned with the canine and the subsequent premolars in most adult thylacinids including Th. cynocephalus (SAM M95, M1959), Th. megiriani (NTM P9618), Nimbacinus dicksoni (Wroe \& Musser 2001, fig. 1b, 4) and Badjcinus turnbulli (Muirhead \& Wroe 1998, fig. 2b). In juvenile Th. cynocephalus the anterior end of $\mathrm{P}^{1}$ is rotated buccally so that the anterior-posterior axis is canted anterobuccally (SAM M1956). This is probably related to tooth crowding in juveniles since adult specimens of $T h$. cynocephalus have normally aligned first upper premolars. In contrast adult specimens of Th. potens have the out-turned condition.

452 Anterior width of the first upper molar greater than its anterior-posterior length. Primitively the 453 anterior-posterior length of $\mathrm{M}^{1}$ exceeds the anterior width (the width from the protocone to the 454 mesiobuccal corner of the tooth) in thylacinids. This condition is present in dasyurids (e.g. 455 Dasyurus maculatus: NTM U7542; Antechinus flavipes: NTM U7566) and all known species of 456 thylacinids (e.g. N. richi: NTM P9973-11; Th. cynocephalus: Woodburne, 1967, table 1) except 457 Th. potens (Woodburne, 1967, table 1) where the anterior width exceeds the anterior-posterior 458 length.

459 Reduced palatal fenestrae. As described by Woodburne (1967) the palatal fenestrae of Th. potens 460 lie below the range of dimensions displayed by Th. cynocephalus, despite coming from a larger 461 palate. Relative to the upper molar row length, the length of a palatal fenestra is about $33 \%$ in $T h$. 462 potens whereas this proportion ranges between $50-58 \%$ in adult Th. cynocephalus (pers. obs. of 463 SAM specimens). All of the few preserved palates of other older thylacinids have relatively large 464 palatal fenestrae like those of Th. cynocephalus (e.g. 55\% in Mutpuracinus archibaldi: NTM 465 P91168-5; 53\% in N. dicksoni: Wroe \& Musser, 2001, fig. 1b; and a fenestra that "extends from

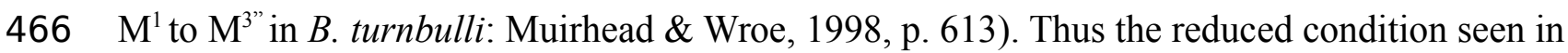
467 Th. potens is, as far as can be determined, an autapomorphy of the species.

468 Absence of a diastema between $P_{1}$ and $P_{2}$. Most thylacinid species possess a diastema between the 469 first and second lower premolars, e.g. B. turnbulli (Muirhead \& Wroe, 1998, fig. 1a), N. dicksoni 470 (Wroe \& Musser, 2001, fig. 2b), Mut.archibaldi (Murray \& Megirian, 2006), Th. macknessi 471 (Muirhead \& Gillespie, 1995, fig. 1a) and Th. cynocephalus (SAM M1959). The sole known 472 exceptions are N. richi (NTM P9612-4) and Th. potens (NTM P4327). Given that N. richi is 473 phylogenetically remote from $T h$. potens, this character can be interpreted as an unambiguous 474 autapomorphy of Th. potens that has convergently evolved in N. richi. 
475 Relative enlargement of $P_{2}$ so that it is longer than $P_{3}$ and $M_{1}$. Primitively the longest lower

476 premolar of thylacinids is the posterior one, here designated $\mathrm{P}_{3}$. This condition is present in

477 Muribacinus gadiyuli (Wroe, 1996, fig. 1.4), B. turnbulli (Muirhead \& Wroe, 1998, table 2), Mut.

478 archibaldi (Murray \& Megirian, 2006, table 2), N. dicksoni (Wroe \& Musser, 2001, fig. 2), $N$.

479 richi (Murray \& Megirian, 2000, table 1), Wabulacinus ridei (Muirhead, 1997), Th. macknessi

480 (Muirhead \& Gillespie, 1995, table 1), Th. megiriani (NTM P4376) and Th. cynocephalus (SAM

481 M95, M1959). Th. potens is unique in having $\mathrm{P}_{2}$ exceed $\mathrm{P}_{3}$ in length (Table 5). Not only does $\mathrm{P}_{2}$

482 exceed $\mathrm{P}_{3}$ but it also exceeds $\mathrm{M}_{1}$ (Table 6), indicating that it is $\mathrm{P}_{2}$ that has undergone relative

483 enlargement.

484 In addition to these characters a further pair of characters are ambiguous autapomorphies of $T h$.

485 potens that due to their shared presence in other taxa phylogenetically close to Th. potens can be

486 equally interpreted as ambiguous autapomorphies of Th. potens or transient synapomorphies of

487 more inclusive clades.

488 Ventrally facing sulcus ventral to the maxillary root of the zygomatic arch. Both the holotype and 489 referred maxillae of $T h$. potens possess a distinct, ventrally facing sulcus that incised along the 490 ventral margin of the root of the zygomatic arch. In NTM P4326 this sulcus starts just above the 491 midlength of $\mathrm{M}^{3}$ and continues posterodorsally onto the base of the zygomatic arch, posterior to $492 \mathrm{M}^{4}$. Although the posterior end of the maxilla is missing in the holotype and only known maxilla 493 of Th. megiriani, the anterior end of a similar sulcus can be seen dorsal to the empty alveolus for

$494 \mathrm{M}^{4}$. No other thylacinids or dasyurids appear to have a comparable sulcus. It can therefore be 495 interpreted as a convergence between Th. potens and Th. megiriani, or a transient synapomorphy 496 of large-bodied Thylacinus species that was reversed in Th. cynocephalus.

$497 P^{2}$ longer than $M^{1}$. Primitively the second and third upper premolars of thylacinids have shorter 498 crowns than the first upper molar. In Ty. rothi, Th. potens and Th. megiriani $\mathrm{P}^{3}$ is enlarged so that 499 it is longer than the first molar. This appears to be a synapomorphy of derived thylacinids

500 including Tyarrpecinus and Thylacinus that is reversed in Th. cynocephalus. However it is only in 501 Ty. rothi and Th. potens that both $\mathrm{P}^{2}$ and $\mathrm{P}^{3}$ are longer than $\mathrm{M}^{1}$. This is either an autapomorphy of

502 Th. potens that is convergently developed in Ty. rothi, or it is a transient synapomorphy that is

503 reversed in Th. megiriani and Th. cynocephalus. The presently unknown anterior upper dentitions

504 of W.ridei and Th. macknessi would decide which one of these alternatives is the more

505 parsimonious.

\section{Variation within Th. potens}

507 The new specimens display some distinctive differences from the original hypodigm described by 508 Woodburne (1967). The new maxilla differs from the holotype in a number of respects, some of 509 which resemble the modern Th. cynocephalus. The holotype of Th. potens displays a wide (4mm) 510 diastema between the canine and $\mathrm{P}^{1}$, whereas no such diastema is present in NTM P4326. Murray 511 (1997) noted the anterior position of the infraorbital foramen above the posterior end of $\mathrm{M}^{1}$ in the 512 holotype specimen of Th. potens and suggested it may be related to facial shortening. However

513 the infraorbital foramen opens above $\mathrm{M}^{2}$ in NTM P4326 as it does in Th. cynocephalus. 
514 Woodburne (1967) also noted that the anterior palate of the holotype was longitudinally bowed,

515 with a broad low ridge separating the anterior depressed area bearing the incisive foramina from

516 the rest of the palate. The anterior palate of NTM P4326 is however simple and flat, like that of

517 Th. cynocephalus. Dentally the new maxilla also displays a few differences from that of the

518 holotype, namely the ectoflexus of $\mathrm{M}^{2}$ is more weakly developed than that of $\mathrm{M}^{3}$, although it is

519 still more prominent than in the $\mathrm{M}^{2}$ of Th. cynocephalus. Lastly Woodburne (1967) noted that $\mathrm{M}^{2}$

520 and $\mathrm{M}^{3}$ were subequal in size in the holotype, with $\mathrm{M}^{3}$ being slightly shorter than $\mathrm{M}^{2}$. In NTM

521 P4326 $\mathrm{M}^{3}$ exceeds $\mathrm{M}^{2}$ in both length and width (Table 4), although the discrepancy between the

522 two molars is not as great as that displayed by Th. cynocephalus.

523 Even more dramatic differences can be seen between Woodburne's dentary and the new dentary.

524 As Woodburne (1967) observed, the paratype dentary fragment of Th. potens has an unusually

525 deep dentary below the posterior molars, both in absolute measurements and relative to the length

526 of the posterior molars. The depth of UCMP 66206 below M4 is $37.0 \mathrm{~mm}$, or 2.40 times the

527 length of $\mathrm{M}_{4}$. In contrast the same measurement is $31.2 \mathrm{~mm}$, or 1.71 times the length of $\mathrm{M}_{4}$, in

528 NTM P4327 which lies within the range displayed by a sample of recent Th. cynocephalus (Table

529 2). Further differences between these specimens can be seen in the teeth. Firstly, there is a well-

530 defined precingulid on $\mathrm{M}_{3-4}$ of NTM P4327, whereas Woodburne (1967,pg. 35) indicated that

531 there is "only a faint suggestion of a cingulum" in this position on the $\mathrm{M}_{3}$ of UCMP 66206.

532 Secondly the talonid of $\mathrm{M}_{3}$ is not transversely reduced in NTM P4327 whereas it is distinctly

533 narrower than the trigonid in UCMP 66206. The latter character is another feature that NTM

534 P4327 shares with Th. cynocephalus.

535 On the basis of these comparisons it would be prudent to question whether the new specimens

536 truly belong to Th. potens, or infact represent a taxon that is more closely related to $T h$.

537 cynocephalus. The latter hypothesis is considered less likely than the former for two reasons.

538 Firstly the new specimens share apomorphic character states with Th. potens that are not seen in

539 Th. cynocephalus. These include: molar row lengths exceeding those of Th. cynocephalus (both

540 NTM P4326 and P4327, see below); anterior end of $\mathrm{P}^{1}$ out-turned (NTM P4326); presence of a

541 sulcus on the ventral margin of the maxillary root of the zygomatic arch (NTM P4326); $\mathrm{P}^{2}$ longer

542 than $\mathrm{M}^{1}$ (NTM P4326). Although the type series of Th. potens lacked an anterior end of a dentary,

543 the presence of an enlarged $\mathrm{P}_{2}$ in NTM P4327would match the derived condition of an enlarged

544 second premolar seen in the upper dentition. In contrast, the similarities shared between these

545 new specimens and Th. cynocephalus are symplesiomorphies that are general to thylacinids. Thus

546 whatever NTM P4326 and P4327 are, their relationship appears to be closer to Th. potens than to

547 any other known thylacinid. Secondly if one were to treat the new specimens as representing a

548 second taxon then this would imply two, closely-related, large-bodied apex predators living as

549 contemporaries in the same local fauna. This is a most unlikely situation.

550 Thus it would appear that Th. potens is a variable species. While much of this variation does not

551 appear unusual in comparison to the variation displayed by historic specimens of $T h$.

552 cynocephalus or other extant dasyuromorph species, the variation seen in the ratio of dentary

553 depth to $\mathrm{M}_{4}$ length is unusually large in Th. potens. This ratio ranges from 1.49 to 1.76 in a

554 historic sample of nine adult Th. cynocephalus, compared to the range of 1.8 to 2.4 seen in just

PeerJ reviewing PDF | (v2014:03:1793:1:0:NEW 30 Jul 2014) 
555 two Th. potens specimens. Given that both the new dentary and Woodburne's specimen show

556 complete eruption of all teeth and an advanced stage of tooth wear it is apparent that they

557 represent mature individuals. Therefore ontogenetic differences cannot account for the

558 differences in relative mandibular depth. A larger sample size is required to test the possibility

559 that the observed variation is the result of sexual dimorphism. Sexual dimorphism is known to

560 have existed in Th. cynocephalus with males having linear skull dimensions 13 to 86\% larger

561 than those of females (Jones, 1997)

562 Phylogenetic position of $T h$. potens

563 The discovery of the anterior end of the dentary of Th. potens revealed an unexpected

564 plesiomorphic character state. All three premolars are set adjacent to one another, with no

565 diastemata between them or the following $\mathrm{M}_{1}$. Diastemata occur between P2 and P3 of all other

566 species of Thylacinus but are absent from more basal thylacinids such as W. ridei (Muirhead,

567 1997), Mut. archibaldi (Murray \& Megirian, 2006) and B. turnbulli (Muirhead \& Wroe, 1998). A

568 number of other previously known plesiomorphies distinguish Th. potens from other Thylacinus

569 species, these include the retention of a precingulum on $\mathrm{M}^{3}, \mathrm{M}^{3}$ that is slightly wider than it is

570 long, and $\mathrm{M}^{2}$ and $\mathrm{M}^{3}$ that are subequal in length. These character states were included in a

571 cladistic analysis to test whether the additional data was enough to cause Th. potens to fall

572 outside the genus Thylacinus.

573 The analysis returned 2 most-parsimonious trees of 88 steps. The strict consensus of the two trees

574 is well-resolved (Fig. 17A). The only polytomy, encompasses the base of Thylacinus and the two

575 taxa found to be most closely related to this genus, i.e. W. ridei and Ma. muirheadae. Inspection

576 of the trees reveals that is the position of Ma. muirheadae that varies between the two. This is

577 unsurprising given that this species is known from just a single tooth, making it the most poorly-

578 known thylacinid and only scorable for $21 \%$ of the characters used in this analysis. If $M a$.

579 muirheadae is pruned a posteriori from the most parsimonious trees, a single, fully-resolved,

580 reduced consensus tree is obtained.

581 The two most parsimonious trees both resolve Th. potens as the sister taxon to the other large-

582 bodied late Neogene species (Th. cynocephalus and Th. megiriani) within the genus Thylacinus

583 (Figure 17), supporting all previous assessments of the relationships of this species. The clade

584 uniting the three large Thylacinus species has a moderate level of bootstrap support (69\%) but

585 this value is lowered by the instability of Ma. muirheadae. When a second bootstrap analysis is

586 conducted, with Ma. muirheadae excluded, the bootstrap support for this clade jumps to $83 \%$,

587 indicating it is a robust result. Thus the plesiomorphic characteristics of Th. potens that are listed

588 above are interpreted as character reversals.

589 Size of Thylacinus potens

590 While several authors have noted the greater robustness and likely greater size of Th. potens

591 relative to the modern Th. cynocephalus (e.g. Woodburne, 1967; only Wroe (2001) has attempted

592 a quantatitive estimate of the body mass of Th. potens. He found the holotype specimen to have

593 come from an individual weighing $38.7 \mathrm{~kg}$ but noted that the estimate was based on the combined

PeerJ reviewing PDF | (v2014:03:1793:1:0:NEW 30 Jul 2014) 
594 length of $\mathrm{M}^{1-3}$ and an assumption of geometric similitude to Th. cynocephalus. The results of the

595 size estimates for the new specimens are summarised in Table 7.

596 As can be seen, the different estimates for each specimen are remarkably close to one another 597 with the exception of the estimate based upon regression of the width of $\mathrm{M}^{2}$. The estimate of 121

$598 \mathrm{~kg}$ is clearly far too high and indicates that Th. potens had relatively broader second upper molars 599 in comparison to other dasyuromorphians.

600 It is also interesting to note that all of the estimates exceed the value of $38.7 \mathrm{~kg}$ that Wroe (2001) 601 obtained for the holotype of Th. potens by inferring geometric similitude with Th. cynocephalus.

602 While the estimates based on the regressions of Myers come with the caveat that they extrapolate 603 beyond the sample used to generate the regression, they do support the hypothesis that Th. potens 604 attained a larger size than the modern thylacine which had an average body weight of $29.5 \mathrm{~kg}$ 605 (Paddle, 2000) and a maximum reconstructed weight of 35kg (Moeller, 1968).

606 However there is the additional caveat that these estimates assume that Th. potens had not 607 evolved unusual body proportions that strongly departed from geometric similitude with $T h$. 608 cynocephalus or the scaling of other dasyuromorphians. Relatively few postcranial elements for 609 Th. potens are known and are still under study by the author. However, an adult humerus was 610 recovered in Shattered Dreams close to NTM P4326 and NTM P4327 and is smaller than average 611 for Th. cynocephalus and hints that the proportions of Th. potens may have indeed been unusual. 612 Further study of other postcranial remains is required to determine if this humerus is typical of 613 Th. potens or from an unusually small individual.

\section{Palaeobiology}

615 The sample of Th. potens teeth display heavy damage and wear including the wearing down of $\mathrm{P}^{2}$ 616 to a rounded stump, the strongly blunted protocone of $\mathrm{P}^{3}$, the virtual obliteration of the paracones 617 from $\mathrm{M}^{2}$ and $\mathrm{M}^{3}$ in NTM P4326, the wearing down of $\mathrm{M}^{2}$ to a single flat plane in NTM P4379

618 (Fig. 11), the virtual obliteration of the protocone by wear in NTM P4516 and the almost

619 complete loss of the crown of $\mathrm{M}_{2}$ in NTM P4327 (Figs. 12, 13). In comparison, a sample of eight 620 adult skulls of Th. cynocephalus (SAM M95, M922, M1953, M1954, M1955, M1959, M1960

621 and M665/001) show no premolars worn to rounded stumps, no molars that have been worn to a

622 flat plane, no paracones or protocones obliterated by wear, only one instance of a lower molar 623 cusp ( $\mathrm{M}_{4}$ paraconid) missing due to breakage and just one instance of a cheek tooth missing due 624 to pre-mortem breakage. These observations strongly suggest that Th. potens were much harder 625 on their cheek teeth than Th. cynocephalus and may have been indulging in durophagy, quite 626 possibly bone-cracking, a feeding style that Th. cynocephalus was ill-equipped to perform (Attard 627 et al., 2011). It is somewhat puzzling then that the teeth of Th. potens do not show a strong trend 628 towards bone-cracking adaptations. For example bone-cracking mammals tend to develop the 629 following features: well developed cingula and cingulids; broad, low crowned premolars and 630 lower molars, lower broader molar cusps and a migration of the molar cusps toward the centre of 631 the tooth crowns (Wroe, 1998). Th. potens shows no trend towards these features over the 632 character states present in thylacinids basally. Thus it is possible that frequent bone cracking was 
633 a relatively new behaviour in Th. potens and that morphological specialisations had yet been

634 given sufficient time to evolve. Alternatively the few preserved individuals known for this

635 species may have been exhibiting exceptional behaviour, possibly related to the unusual

636 environmental conditions associated with the Alcoota mass death assemblage.The question can

637 only be explored with the collection of a larger sample of specimens, more complete specimens

638 or, ideally, the location of Th. potens specimens in a different depositional setting.

\section{Acknowledgements}

640 The new maxilla and dentary which form the basis of this paper were discovered in a new pit 641 ('Shattered Dreams') which was opened thanks to the generous loan of a backhoe and licensed 642 operator from Central Desert Shire, Northern Territory. I am deeply indebted to Glenn Marshall

643 for making this loan possible. The specimens themselves were found and patiently excavated by

644 Jared Archibald. I also wish to thank Catherine Kemper and Ben McHenry of the South

645 Australian Museum for allowing me access to thylacinid specimens in their care. Karen Black

646 and Gavin Prideaux provided thoughtfull reviews which improved the quality of the final paper.

647 All photographs used in this paper were taken by Steven Jackson.

\section{References}

649 Archer M, Rich TH. 1982. Results of the Ray E. Lemley expeditions. Wakaleo alcootaensis n. sp. 650 (Thylacoleonidae, Marsupialia), a new marsupial lion from the Miocene of the Northern Territory 651 with a consideration of early radiation in the family. In: Archer M, ed. Carnivorous Marsupials. 652 Sydney: Royal Zoological Society of New South Wales, 495-502.

653 Attard MRG, Chamoli U, Ferrara TL, Rogers TL,Wroe S. 2011. Skull mechanics and

654 implications for feeding behaviour in a large marsupial carnivore guild: the thylacine, Tasmanian 655 devil and spotted-tailed quoll. Journal of Zoology 285: 292-300.

656 Beck RMD. 2008. A dated phylogeny of marsupials using a molecular supermatrix and multiple 657 fossil constraints. Journal of Mammalogy 89: 175-189.

658 Bonaparte CLJL. 1838. Synopsis vertebratorium systematis. Nuovi Annual, Science and Nature, 659 Bologna 2: 105-133.

660 Dawson L. 1982. Taxonomic status of fossil thylacines (Thylacinus, Thylacinidae, Marsupialia) 661 from late Quaternary deposits in eastern Australia. In: Archer M, ed. Carnivorous Marsupials. 662 Sydney: Royal Zoological Society of New South Wales, 527-536.

663 Duan, N. 1983. Smearing estimate: a nonparametric re-transformation method. Journal of the 664 American Statistical Association 78: 605-610.

665 Flower, WH. 1867. On the development and succession of the teeth in the Marsupialia. 666 Philosophical Transactions of the Royal Society of London 157: 631-641. 
667 Gill T. 1872. Arrangement of the families of mammals with analytical tables. Smithsonian

668 Miscellaneous Collections 2: 1-98.

669 Jones M. 1997. Character displacement in Australian dasyurid carnivores: Size relationships and 670 prey size patterns. Ecology 78: 2569-2587.

671 Krajewski C, Buckley L, \& Westerman M. 1997. DNA phylogeny of the marsupial wolf resolved. 672 Proceedings of the Royal Society of London B 264: 911-917.

673 Luckett, WP. 1993. An ontogenetic assessment of dental homologies in therian mammals. In: 674 Szalay FS, Novacek MJ \& McKenna MC, eds. Mammal phylogeny. New York: Springer, 182675204.

676 Megirian D. 2000. Report on shallow augering at the MAGNT Alcoota fossil reserve, June and 677 August, 1998. MAGNT Research Report 7: 1-19.

678 Megirian D, Prideaux GJ, Murray PF, Smit N. 2010. An Australian land mammal age 679 biochronological scheme. Paleobiology 36: 658-671.

680 Miller W, Drautz DI, Janecka JE et al. 2009. The mitochondrial genome sequence of the 681 Tasmanian tiger (Thylacinus cynocephalus). Genome Research 19: 213-220.

682 Moeller H. 1968. Zur Frage der Parallelerscheinungen bei Metatheria und Eutheria. 683 Vergleichende Untersuchungen an Beutelelwolf und Wolf. Zeitschrift für Wissenschaftliche 684 Zoologie 177: 283-392

685 Muirhead J. 1992. A specialized thylacinid, Thylacinus macknessi, (Marsupialia: Thylacinidae) 686 from Miocene deposits of Riversleigh, northwestern Queensland. Australian Mammalogy 15: 6768776.

688 Muirhead J. 1997. Two new Early Miocene thylacines from Riversleigh, northwestern 689 Queensland. Memoirs of the Queensland Museum 41: 367-377.

690 Muirhead J, Gillespie AK. 1995. Additional parts of the type specimen of Thylacinus macknessi 691 (Marsupialia: Thylacinidae) from Miocene deposits of Riversleigh, northwestern Queensland. 692 Australian Mammalogy 18: 55-60.

693 Muirhead J, Wroe S. 1998. A new genus and species, Badjcinus turnbulli (Thylacinidae: 694 Marsupialia), from the late Oligocene of Riversleigh, northern Australia, and an investigation of 695 thylacinid phylogeny. Journal of Vertebrate Paleontology 18: 612-611.

696 Murray PF. 1997. Thylacinus megiriani, a new species of thylacine (Marsupialia: Thylacinidae) 697 from the Ongeva Local Fauna of Central Australia. Records of the South Australian Museum 30: 698 43-61. 
699 Murray PF, Megirian D. 1992. Continuity and contrast in middle and late Miocene vertebrate

700 communities from the Northern Territory. The Beagle: Records of the Museums and Art Galleries

701 of the Northern Territory 9: 195-218.

702 Murray PF, Megirian D. 2000. Two new genera and three new species of Thylacinidae

703 (Marsupialia) from the Miocene of the Northern Territory, Australia. The Beagle: Records of the

704 Museums and Art Galleries of the Northern Territory 16: 145-162.

705 Murray PF, Megirian D. 2006. Cranial morphology of the Miocene thylacinid Mutpuracinus

706 archibaldi (Thylacinidae, Marsupialia) and its relationships within the Dasyuromorphia.

707 Alcheringa Special Issue 1: 229-276.

708 Myers TJ. 2001. Prediction of marsupial body mass. Australian Journal of Zoology 49: 99-118.

709 Paddle R. 2000. The Last Tasmanian Tiger: the history and extinction of the thylacine.

710 Cambridge: Cambridge University Press

711 Ride, WDL. 1964. A review of Australian fossil marsupials. Journal of the Royal Society of

712 Western Australia 47: 97-131.

713 Stirton RA, Woodburne MO, Plane MD. 1967. A phylogeny of the Tertiary Diprotodontidae and 714 its significance in correlation. Bulletin of the Bureau of Mineral Resources, Geology and 715 Geophysics, Australia 85: 149-160.

716 Swofford DL. 2002. PAUP* Phylogenetic Analysis Using Parsimony (*and Other Methods).

717 Version 4. Sinauer Associates, Sunderland, MA.

718 Wilkinson M. 1994. Common cladistic information and its consensus representation: reduced

719 Adams and reduced cladistic consensus trees and profiles. Systematic Biology 43: 343-368.

720 Woodburne MO. 1967. The Alcoota Fauna, central Australia. Bulletin of the Bureau of Mineral

721 Resources Geology and Geophysics, Australia 87: 1-187.

722 Wroe S. 1996. Muribacinus gadiyuli, (Thylacinidae: Marsupialia), a very plesiomorphic

723 thylacinid from the Miocene of Riversleigh, northwestern Queensland, and the problem of

724 paraphyly for the Dasyuridae (Marsupialia). Journal of Paleontology 70: 1032-1044.

725 Wroe S. 1998. A new genus and species of 'bone-cracking' daysurid (Marsupialia) from the

726 Miocene of Riversleigh, northwestern Queensland. Alcheringa 22: 277-84.

727 Wroe S. 1999. The geologically oldest dasyurid, from the Miocene of Riversleigh, north-west

728 Queensland. Palaeontology 42: 501-527.

729 Wroe S. 2001. Maximucinus muirheadae, gen. et sp. nov. (Thylacinidae: Marsupialia), from the

730 Miocene of Riversleigh, north-western Queensland, with estimates of body weights for fossil

731 thylacinids. Australian Journal of Zoology 49: 603-614. 
732 Wroe S. 2003. Australian marsupial carnivores: Recent advances in palaeontology. In: Jones M,

733 Dickman C \& Archer M, eds. Predators with Pouches: The biology of marsupial carnivores.

734 Collingwood: CSIRO Publishing. 102-123.

735 Wroe S, Musser A. 2001. The skull of Nimbacinus dicksoni (Thylacinidae: Marsupialia).

736 Australian Journal of Zoology 49: 487-514.

\section{Appendix 1. Character list.}

738

739

740

741

742

743

744

745

746

747

748

749

750

751

752

753

754

755

756

757

758

759

760

761

762

763

764

765

766

767

768

769

770

771

1. Relationship of jugal to infraorbital foramen: jugal widely separated from the margin of the infraorbital foramen (0); maxilla-jugal suture passes very close to the margin of the infraorbital foramen (1); jugal contributes to the posterior margin of the infraorbital foramen (2). Modified from character 3 in Muirhead and Wroe (1998). Character is treated as ordered.

2. Position of the infraorbital foramen: infraorbital foramen is dorsal to $M^{1}(0)$; infraorbital foramen is dorsal to $\mathrm{M}^{2}$ (1). Character 12 in Murray (1997).

3. Presence or absence of a sulcus along the ventral margin of the maxillary zygomatic root: sulcus absent (0); sulcus present (1). Character is new.

4. Enclosure of the primary foramen ovale: foramen ovale partly bordered by the periotic (0); foramen ovale completely enclosed by the alisphenoid, excluding periotic from its margin (1). Character 5 in Muirhead and Wroe (1998).

5. Relationship of the alisphenoid and petrosal tympanic processes: petrosal tympanic process contacts the alisphenoid tympanic process (0); petrosal tympanic process reduced or absent, so that it does not contact the alisphenoid tympanic process (1). Character 9 in Muirhead and Wroe (1998).

6. Position of $\mathrm{P}^{2}: \mathrm{P}^{2}$ closer to $\mathrm{P}^{3}$ than to $\mathrm{P}^{1} ; \mathrm{P}^{2}$ equidistant between $\mathrm{P}^{3}$ and $\mathrm{P}^{1}$. Character is new.

7. Anterior-posterior length of $\mathrm{P}^{2}: \mathrm{P}^{2}$ shorter than $\mathrm{M}^{1} ; \mathrm{P}^{2}$ longer than $\mathrm{M}^{1}$. Character is new.

8. Anterior-posterior length of $\mathrm{P}^{3}: \mathrm{P}^{3}$ shorter than $\mathrm{M}^{1} ; \mathrm{P}^{3}$ longer than $\mathrm{M}^{1}$. Character is new.

9. Presence or absence of a posterolingual cuspule on $\mathrm{P}^{3}$ : cuspule absent (0); cuspule present (1). Character 7 in Wroe and Musser (2001).

10. Development of precingulum on $\mathrm{M}^{1}$ : precingulum present and complete extending from the anterobuccal corner to a point anterior to the base of the protocone $(0)$; precingulum present but incomplete, extending from anterobuccal corner to a point anterior to the base of the paracone (1); precingulum absent (2). Character 12 in Muirhead and Wroe (1998). Character is treated as ordered.

11. Presence or absence of a precingulum on $\mathrm{M}^{3}$ : precingulum present (0); precingulum absent (1). Character is new.

12. Orientation of the preparacrista on $\mathrm{M}^{1}$ : preparacrista perpendicular to the long axis of $\mathrm{M}^{1}$ (0); preparacrista angled anterobuccally relative to the long axis of $\mathrm{M}^{1}$ (1). Character 16 in Muirhead and Wroe (1998).

13. Presence or absence of a postcingulum on $\mathrm{M}^{1}$ : postcingulum present (0); postcingulum absent (1). Character 25 in Wroe and Musser (2001).

PeerJ reviewing PDF | (v2014:03:1793:1:0:NEW 30 Jul 2014) 
772

773

774

775

776

777

778

779

780

781

782

783

784

785

786

787

788

789

790

791

792

793

794

795

796

797

798

799

800

801

802

803

804

805

806

807

808

809

810

811

812

813

814

815

14. Development of the ectoflexus on $\mathrm{M}^{2}$ and $\mathrm{M}^{3}$ : ectoflexus well-developed (0); ectoflexus extremely reduced or absent (1). Modified from figure 11 in Murray (1997).

15. Size of the paracone in the upper molars: large, approaching the size of thekhyu metacone (0); significantly reduced, much less than the size of the metacone (1). Modified from character 10 in Muirhead and Wroe (1998).

16. Shape of the centrocrista of $\mathrm{M}^{1}$ in occlusal view: sharply angled (0); obtusely angled (1); straight (2). Modified from character 15 in Muirhead and Wroe (1998). Character is treated as ordered.

17. Shape of the centrocrista of $\mathrm{M}^{2}$ and $\mathrm{M}^{3}$ in occlusal view: sharply angled (0); obtusely angled (1); straight (2). Modified from character 15 in Muirhead and Wroe (1998). Character is treated as ordered.

18. Elongation of the postmetacrista in upper molars: postmetacrista not elongate with the metastylar wing occupying $40-48 \%$ of the tooth length (0); postmetacrista mildly elongated with the metastylar wing occupying $48-52 \%$ of the tooth length (1); postmetacrista strongly elongated with the metastylar wing extending over $52 \%$ of the length of the tooth (2). Modified from character 14 in Muirhead and Wroe (1998). Character is treated as ordered.

19. Presence or absence of the protoconule on the upper molars: protoconule present (0); protoconule absent (1). Character 14 in Wroe and Musser (2001).

20. Presence or absence of the metaconule on the upper molars: metaconule present (0); metaconule absent (1). Character 15 in Wroe and Musser (2001).

21. Size of $\mathrm{M}^{3}$ relative to $\mathrm{M}^{2}: \mathrm{M}^{3}$ and $\mathrm{M}^{2}$ are subequal (0); $\mathrm{M}^{3}$ is distinctly larger than $\mathrm{M}^{2}(1)$. Character is new.

22. Shape of $\mathrm{M}^{3}: \mathrm{M}^{3}$ is as wide as, or wider than it is long (0): $\mathrm{M}^{3}$ is longer than it is wide (1). Character is new.

23. Size of stylar cusp B on $\mathrm{M}^{1}$ and $\mathrm{M}^{2}$ : stylar cusp B is well-developed (0); stylar cusp B is highly reduced or absent (1). Modified from character 11 in Muirhead and Wroe (1998).

24. Presence or absence of stylar cusp C on $\mathrm{M}^{1}$ :stylar cusp $\mathrm{C}$ is absent (0); stylar cusp C is present (1). Modified from character 21 in Wroe and Musser (2001).

25. Presence or absence of stylar cusp $\mathrm{C}$ on $\mathrm{M}^{2}$ and $\mathrm{M}^{3}$ : stylar cusp $\mathrm{C}$ is present (0); stylar cusp C is absent (1). Modified from character 21 in Wroe and Musser (2001).

26. Development of stylar cusp D on $\mathrm{M}^{2}$ : stylar cusp D is present and large (0); stylar cusp D is reduced to a slight bulge or a bump (1); stylar cusp D is absent (2). Character is treated as ordered.

27.Presence or absence of stylar cusp D on $\mathrm{M}^{3}$ : stylar cusp D is present (0); stylar cusp D is absent (1). Modified from character 18 in Wroe and Musser (2001).

28. Presence or absence of stylar crest on $\mathrm{M}^{3}$ : stylar crest present (0); stylar crest absent (1). Modified from character 7 in Muirhead (1997).

29. Presence or absence of a diastema between $\mathrm{p}_{1}$ and $\mathrm{p}_{2}$ : diastema present ( 0 ); diastema absent (1). Character 22 in Muirhead and Wroe (1998).

30. Presence or absence of a diastema between $\mathrm{p}_{2}$ and $\mathrm{p}_{3}$ : diastema absent (0); diastema present (1). Character 23 in Muirhead and Wroe (1998)

31. Anterior-posterior length of $p_{3}$ relative to $p_{2}$ : $p_{3}$ shorter than $p_{2}(0)$; $p_{3}$ longer than $p_{2}(1)$. Modified from character 30 in Muirhead and Wroe (1998). 
32. Presence or absence of a diastema between $\mathrm{p}_{3}$ and $\mathrm{m}_{1}$ : diastema absent (0); diastema present (1). Character is new.

33. Development of metaconid in $\mathrm{m}_{1}$ : metaconid is a well-developed, distinct cusp (0);

819

820

821

822

823

824

825

826

827

828

829

830

831

832

833

834

835

836

837

838

839

840

841

842

843

844

845

\section{Appendix 2. Tree Description}

847 The tree described here is the reduced strict cladistic consensus, which has had Maximucinus

848 muirheadae pruned from it a posteriori. Designated letters for each clade respond to those in

849 Figure 16B. Character state changes are given in brackets after each character number. Characters

850 that have a CI of 1 (i.e. change only once and are free of homoplasy) are marked with an asterix.

851 Clade A. Thylacinidae

852 Content. Muribacinus gadiyuli, Badjcinus turnbulli, Ngamalacinus timmulvaneyi, Mutpuracinus

853 archibaldi, Nimbacinus dicksoni, Nimbacinus richi, Tyarrpecinus rothi, Wabulacinus ridei,

854 Thylacinus macknessi, Thylacinus potens, Thylacinus megiriani and Thylacinus cynocephalus.

PeerJ reviewing PDF | (v2014:03:1793:1:0:NEW 30 Jul 2014) 
855 Unambiguous synapomorphies. Character 9 (0 to 1): presence of a posterolingual cuspule on $\mathrm{P}^{3}$.

856 Reversed at clade K (acctran) or in Th. cynocephalus (deltran). Ambiguous synapomorphy under 857 acctran optimisation. Character 5 (0 to 1): Petrosal tympanic process strongly reduced so that it 858 does not contact the alisphenoid tympanic process. Reversed in Mutpuracinus archibaldi.

859 Clade $B$

860 Content. Badjcinus turnbulli, Ngamalacinus timmulvaneyi, Mutpuracinus archibaldi,

861 Nimbacinus dicksoni, Nimbacinus richi, Tyarrpecinus rothi, Wabulacinus ridei, Thylacinus

862 macknessi, Thylacinus potens, Thylacinus megiriani and Thylacinus cynocephalus.

863 Unambiguous synapomorphies. Character 31 (0 to 1): $\mathrm{P}_{3}$ is longer than $\mathrm{P}_{2}$. Reversed in 864 Thylacinus potens. Character 33 (0 to 1)*: Metaconid of $\mathrm{M}_{1}$ is reduced to a small cuspule. 865 Character 35 (0 to 1$)^{*}$ : Anterior end of cristid obliqua extends partway up the posterior slope of 866 the protoconid.

867 Ambiguous synapomorphy under deltran optimisation. Character 5 (0 to 1): Petrosal tympanic 868 process strongly reduced so that it does not contact the alisphenoid tympanic process. Reversed in 869 Mutpuracinus archibaldi.

870 Clade C

871 Content. Badjcinus turnbulli and Ngamalacinus timmulvaneyi.

872 Unambiguous synapomorphies. Character 37 (0 to 1)*: presence of a carnassial notch in the 873 hypocristid. Character 40 (0 to 1): presence of a posterior cingulid on $\mathrm{M}_{4}$. Convergent in $T h$. 874 macknessi.

875 Clade D

876 Content. Mutpuracinus archibaldi, Nimbacinus dicksoni, Nimbacinus richi, Tyarrpecinus rothi, 877 Wabulacinus ridei, Thylacinus macknessi, Thylacinus potens, Thylacinus megiriani and 878 Thylacinus cynocephalus.

879 Unambiguous synapomorphies. Character 4 (0 to 1$)^{*}$ : primary foramen ovale completely 880 enclosed by the alisphenoid. Character 13 ( 0 to 1$)$ : loss of the postcingulum on $\mathrm{M}^{1}$. Reversed in 881 Thylacinus megiriani.

882 Clade $E$

883 Content. Mutpuracinus archibaldi, Nimbacinus dicksoni, Nimbacinus richi.

884 Unambiguous synapomorphy. Character 24 (0 to 1): Presence of stylar cusp C on $\mathrm{M}^{1}$. Convergent 885 in Barinya wangala and Thylacinus megiriani. 
887 Content. Nimbacinus dicksoni, Nimbacinus richi.

888 Unambiguous synapomporphy. Character 30 (0 to 1): Presence of a diastema between $\mathrm{P}_{2}$ and $\mathrm{P}_{3}$. 889 Convergent in Muribacinus gadiyuli, and in Thylacinus with a reversal in Th. potens (acctran), or 890 convergent in Muribacinus gadiyuli, Thylacinus macknessi and clade K (deltran).

\section{Clade $G$}

892 Content. Tyarrpecinus rothi, Wabulacinus ridei, Thylacinus macknessi, Thylacinus potens, 893 Thylacinus megiriani and Thylacinus cynocephalus.

894 Unambiguous synapomorphies. Character 8 (0 to 1$): \mathrm{P}^{3}$ longer than $\mathrm{M}^{1}$. Convergent in Barinya 895 wangala and reversed in Thylacinus cynocephalus. Character 16 (0 to 1)*: Wide, obtuse angle 896 between the postparacrista and premetacrista of $\mathrm{M}^{1}$, creating a nearly straight centrocrista.

897 Character 18 ( 0 to 1$)^{*}$ : mild elongation of the postmetacrista in $\mathrm{M}^{2}$ and $\mathrm{M}^{3}$ so that it is greater 898 than $48 \%$ of the total length of the tooth. Character 38 ( 0 to 1$)^{*}$ : Loss of a distinct entoconid.

899 Ambiguous synapomorphies under acctran optimisation. Character 3 (0 to 1): Presence of sulcus 900 along the ventral margin of maxillary zygomatic root. Reversed in Thylacinus cynocephalus. 901 Character 7 (0 to 1): $\mathrm{P}^{2}$ longer than $\mathrm{M}^{1}$ Reversed in clade K. Character 10 (0 to 1): Reduction of 902 the precingulum of $\mathrm{M}^{1}$ to an incomplete cingulum that does not reach the talon. Reversed to 903 complete precingulum in Thylacinus, and then reduced to total loss in clade K. Chartacter 20 (0 904 to 1): Loss of metaconule on $\mathrm{M}^{1}$ to $\mathrm{M}^{3}$. Reversed in Thylacinus and then lost again in clade $\mathrm{K}$. 905 Character 33 (1 to 2): Metaconid of $\mathrm{M}_{1}$ entirely lost. Convergent in B. turnbulli. Character 34 (0 906 to 1$)^{*}$ : Reduction of metaconids on $\mathrm{M}_{2}$ to $\mathrm{M}_{4}$ to minute cuspules. Character 40 (0 to 1$)^{*}$ : Loss of 907 postcingulid on $\mathrm{M}_{1}$ to $\mathrm{M}_{3}$.

908 Clade H

909 Content. Wabulacinus ridei, Thylacinus macknessi, Thylacinus potens, Thylacinus megiriani and 910 Thylacinus cynocephalus.

911 Unambiguous synapomorphies. Character 12 (0 to 1$)^{*}$ : preparacrista on $\mathrm{M}^{1}$ is angled 912 anterobuccally. Character 16 (1 to 2)*: Centrocrista of $\mathrm{M}^{1}$ is straight and parallel with anterior913 posterior axis of the tooth. Character 17 (0 to 1$)^{*}$ : Wide, obtuse angle between the postparacrista 914 and premetacrista of $\mathrm{M}^{2}$ and $\mathrm{M}^{3}$, creating a nearly straight centrocrista. Character 19 (0 to 1): 915 Loss of protoconule on upper molars. Convergent in Nimbacinus richi. Character 23 (0 to 1): 916 Stylar cusp B on $\mathrm{M}^{1}$ is highly reduced to absent. Convergent in Badjcinus turnbulli. Character 25

917 (0 to 1): Loss of stylar cusp $\mathrm{C}$ on $\mathrm{M}^{2}$ and $\mathrm{M}^{3}$. Convergent in Muribacinus gadiyuli. 
918 Ambiguous synapomorphies under Deltran optimisation. Character 40 (0 to 1)*: Loss of

919 postcingulid on $\mathrm{M}_{1}$ to $\mathrm{M}_{3}$. Character 34 (0 to 1)*: Reduction of metaconids on $\mathrm{M}_{2}$ to $\mathrm{M}_{4}$ to minute

920 cuspules.

921 Clade I. Thylacinus

922 Unambiguous synapomorphy. Character 36 (0 to 1$)$ presence of a carnassial notch in the cristid 923 obliqua. Convergent in Ngamalacinus timmulvaneyi.

924 Ambiguous synapomorphies under deltran optimisation. Character 33 (1 to 2): Complete loss of 925 metaconid on $\mathrm{M}_{1}$. Convergent in Badjcinus turnbulli.

926 Ambiguous synapomorphies under acctran optimisation. Character 1 (0 to 1): Maxilla-jugal 927 suture passes very close to the margin of the infraorbital foramen so that only a thin sliver of the 928 maxilla separates the jugal from the foramen. Convergent in Ngamalacinus timmulvaneyi.

929 Character 2 (0 to 1): Infraorbital foramen shifted posteriorly to a position dorsal to $\mathrm{M}^{2}$.

930 Convergent in Muribacinus gadiyuli and Ngamalacinus timmulvaneyi. Character 10 (1 to 0):

931 Presence of a complete precingulum on $\mathrm{M}^{1}$. Reversal of a character that was incompletely lost at 932 clade G. Character 17 (1 to 2)*: Straight centrocrista on $\mathrm{M}^{2}$ and $\mathrm{M}^{3}$. Character 18 (1 to 2)*:

933 Extreme elongation of the postmetacrista so that it is over $52 \%$ of the length of the tooth.

934 Character 20 (1 to 0): Presence of a metaconule on the upper molars. Reversal of a character that 935 was lost at clade G, subsequently lost again in clade K. Character 30 (0 to 1): Presence of a 936 diastema between $\mathrm{P}_{2}$ and $\mathrm{P}_{3}$. Convergent in Thylacinus macknessi, Nimbacinus and Muribacinus 937 gadiyuli.

938 Clade $J$

939 Content. Thylacinus potens, Thylacinus megiriani and Thylacinus cynocephalus.

940 Unambiguous synapomorphies. Character 15 (0 to 1): Paracone of upper molars significantly 941 reduced in comparison to metacone. Convergent in Tyarrpecinus rothi. Character 34 (1 to 2)*: 942 metaconids of $\mathrm{M}_{2}$ to $\mathrm{M}_{4}$ completely lost. Character 35 (1 to 2$)^{*}$ : anterior end of cristid obliqua

943 extends to the tip of the protoconid. Character 39 (0 to 1): $\mathrm{M}_{4}$ is longer than $\mathrm{M}_{3}$. Convergent in

944 Mutpuracinus archibaldi. Character 42 (0 to 1): Increased body mass, so that it is greater than 15 $945 \mathrm{~kg}$.

946 Ambiguous synapomorphies under deltran optimisation. Character 1 (0 to 1): Maxilla-jugal 947 suture passes very close to the margin of the infraorbital foramen so that only a thin sliver of the 948 maxilla separates the jugal from the foramen. Convergent in Ngamalacinus timmulvaneyi. 949 Character 17 ( 1 to 2$)^{*}$ : Straight centrocrista on $\mathrm{M}^{2}$ and $\mathrm{M}^{3}$. Character 18 (1 to 2)*: Extreme 950 elongation of the postmetacrista so that it is over $52 \%$ of the length of the tooth. 


\section{Clade $K$}

952 Content. Thylacinus megiriani, Thylacinus cynocephalus.

953 Unambiguous synapomorphies. Character 10 (0 to 2)*: complete loss of precingulum on $\mathrm{M}^{1}$. 954 Character 11 (0 to 1$)^{*}$ : loss of precingulum on $\mathrm{M}^{3}$. Character 20 (0 to 1$)$ : loss of metaconule on 955 upper molars. Convergent in Tyarrpecinus rothi and Wabulacinus ridei (deltran optimisation) or 956 reversal of a character reacquired in Thylacinus (acctran optimisation). Character 21 (0 to 1)*: $\mathrm{M}^{3}$ 957 greater than $5 \%$ longer than $\mathrm{M}^{2}$. Character $22(0 \text { to } 1)^{*}: \mathrm{M}^{3}$ is longer than it is wide. Character 28 958 (0 to 1$)^{*}$ : loss of stylar crest on $\mathrm{M}^{3}$. Character 32 ( 0 to 1$)^{*}$ : Presence of a diastema between $\mathrm{P}_{3}$ and $959 \mathrm{M}_{1}$.

960 Ambiguous synapomorphies under deltran optimisation. Character 2 (0 to 1): Infraorbital 961 foramen shifted posteriorly to a position dorsal to $\mathrm{M}^{2}$. Convergent in Muribacinus gadiyuli and 962 Ngamalacinus timmulvaneyi. Character 30 (0 to 1): Presence of a diastema between $\mathrm{P}_{2}$ and $\mathrm{P}_{3}$. 963 Convergent in Muribacinus gadiyuli, Nimbacinus and Thylacinus macknessi.

964 Ambiguous synapomorphies under acctran optimisation. Character 7 ( 1 to 0$)$. $\mathrm{P}^{2}$ is shorter than $965 \mathrm{M}^{1}$. Reversal of a character that evolved in clade $\mathrm{G}$. Character 9 (1 to 0 ). Loss of posterolingual 966 cusp on $\mathrm{P}^{3}$. Reversal of a character that evolved in Thylacinidae. 


\section{Table 1 (on next page)}

Terminal taxa

Table 1. Terminal taxa used in the cladistic analysis and their sources of character data (literature and specimens). 
Taxon

Dasyuridae

Muribacinus gadiyuli

Badjcinus turnbulli

Ngamalacinus

timmulvaneyi

Maximucinus

muirheadae

Mutpuracinus

archibaldi

Nimbacinus dicksoni

Nimbacinus richi

Wabulacinus ridei

Tyarrpecinus rothi

Thylacinus macknessi

Thylacinus potens

Thylacinus megiriani

Thylacinus

cynocephalus
Sources

Wroe, 1999 (Barinya wangala); NTM U7542 (Dasyurus maculatus)

Wroe, 1996

Muirhead \& Wroe, 1998

Muirhead, 1997

Wroe, 2001

Murray \& Megirian, 2000, 2006; NTM P907-3; NTM P9612-5

Muirhead \& Archer, 1990; Wroe \& Musser, 2001

Murray \& Megirian, 2000; NTM P9612-4; NTM P9973-11

Muirhead, 1997

Murray \& Megirian, 2000; NTM P98211

Muirhead, 1992; Muirhead \& Gillespie, 1995

Woodburne, 1967; CPC 6746(c); NTM P4326; NTM P4327

Murray, 1997; NTM P4376; NTM P4377; NTM P9618

Murray \& Megirian, 2006; SAM M95, SAM M665/001, SAM M922, SAM

M1952-56, SAM M1959-60. 


\section{Table 2 (on next page)}

Cranial measurements and ratio for Thylacinus species.

Table 2. Selected cranial measurements and ratio of Thylacinus potens and Th. cynocephalaus. $\mathrm{MH}$, vertical height of the maxilla above the mesial end of $\mathrm{P}^{3} ; \mathrm{C}-\mathrm{P}^{3}$, the distance between the mesial margin of the upper canine and the distal margin of $\mathrm{P}^{3} ; \mathrm{MH} / \mathrm{C}$ $P^{3}$, ratio of maxilla height to canine- $P^{3}$ distance; $P^{1}-P^{1}$, transverse distance between the left and right lingual sides of the distal roots of each $\mathrm{P}^{1} ; \mathrm{DD}$, depth of the horizontal ramus of the dentary measured at the level of the mesial end of $\mathrm{M}_{4}$. Measurements in $\mathrm{mm}, \sim$ indicates an approximation due to damage, ${ }^{*}$ indicates a transverse measurement obtained by doubling the distance from the landmark to the midline. Measurements for Th. cynocephalus were obtained from a sample of nine adult specimens held at SAM. 
Th. potens

NTM P4326

44.4

$\sim 66.0$

$67.3 \%$

$19.2^{*}$

NTM P4327

UCMP 66206

Th. cynocephalus

mean

34.6

$28.8-40.7$
52.2

$45.8-58.52$
30.3

37.0

$66.2 \%$

22.1 27.2

range
$63.9 \%-70.5 \% \quad 18.9-23.9$

$22.1-31.0$ 


\section{Table 3(on next page)}

Measurements of upper premolars

Table 3. Measurements of upper premolars of Thylacinus potens and Th. cynocephalus. Data for CPC 6746 and Th. cynocephalus are taken from Woodburne (1967). Measurements for Th. cynocephalus are mean values taken from a sample of six specimens. Measurements are in $\mathrm{mm}, \sim$ indicates an approximation due to damage. $\mathrm{L}=$ mesiodistal length, $\mathrm{W}=$ maximum buccolingual width. 
$\begin{array}{llllll}\mathrm{P}^{1} \mathrm{~L} & \mathrm{P}^{1} \mathrm{~W} & \mathrm{P}^{2} \mathrm{~L} & \mathrm{P}^{2} \mathrm{~W} & \mathrm{P}^{3} \mathrm{~L} & \mathrm{P}^{3} \mathrm{~W}\end{array}$

Th. potens

$\begin{array}{lllllll}\text { NTM P4326 } & \sim 13.3 & 4.8 & 14 . & 6.7 & 15 . & 8.7 \\ & & & 2 & & 8 & \\ \text { NTM P4332 } & - & - & - & - & 16 . & 9.4 \\ & & & & & 7 & \\ \text { CPC 6746 } & - & - & 12 . & 5.5 & 16 . & 8.8 \\ & & & 4 & & 0 & \end{array}$

Th.

cynocephalus

$\begin{array}{lllllll}\text { mean } & 6.2 & 3.3 & 8.3 & 3.8 & 10 . & 5.0\end{array}$

6 


\title{
Table 4(on next page)
}

Measurements of upper molars

\author{
Table 4. Measurements of upper molars of Thylacinus potens and Th. cynocephalus. Data for \\ CPC 6746 and Th. cynocephalus are taken from Woodburne (1967). Measurements for Th. \\ cynocephalus are mean values taken from a sample of six specimens. Measurements are in \\ $\mathrm{mm} . \mathrm{L}=$ mesiodistal length, $\mathrm{W} 1=$ width of the crown from the mesiobuccal corner to the \\ lingual side of the protocone, $\mathrm{W} 2$ = width of the crown from the metastylar corner to the \\ lingual side of the protocone.
}




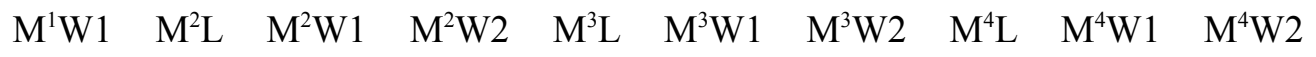

Th. potens

$\begin{array}{lllllllllll}\text { NTM P4326 } & 12.4 & 15.7 & 14.7 & 18.0 & 16.0 & 15.5 & 18.6 & 11.5 & 14.0 & 9.5 \\ \text { NTM P4379 } & - & 16.1 & \sim 14.1 & \sim 17.7 & - & - & - & - & - & - \\ \text { CPC 6746 } & 12.8 & 15.7 & 13.9 & 17.5 & 15.2 & 15.9 & 19.0 & 12.2 & 15.8 & 9.9 \\ \begin{array}{l}\text { Th. } \\ \text { cynocephalus }\end{array} & & & & & & & & & & \\ \text { mean } & 7.8 & 13.2 & 10.0 & 15.0 & 15.1 & 12.0 & 17.8 & 9.7 & 12.6 & 7.8\end{array}$

PeerJ reviewing PDF | (v2014:03:1793:1:0:NEW 30 Jul 2014) 


\section{Table 5 (on next page)}

Measurements of lower premolars

Table 5. Measurements of lower premolars of Thylacinus potens and Th. cynocephalus.

Measurements for Th. cynocephalus are mean values taken from a sample of six specimens.

Measurements are in $\mathrm{mm} . \mathrm{L}=$ mesiodistal length, $\mathrm{W}=$ maximum buccolingual width. 
$\begin{array}{llllll}\mathrm{P}_{1} \mathrm{~W} & \mathrm{P}_{1} \mathrm{~L} & \mathrm{P}_{2} \mathrm{~W} & \mathrm{P}_{2} \mathrm{~L} & \mathrm{P}_{3} \mathrm{~W} & \mathrm{P}_{3} \mathrm{~L}\end{array}$

Th. potens

NTM P4327

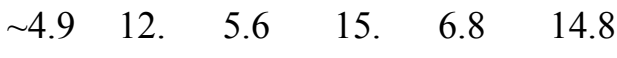

$T h$.

cynocephalus

mean

$\begin{array}{llllll}3.4 & 6.0 & 4.1 & 9.1 & 5.0 & 10.6\end{array}$

PeerJ reviewing PDF | (v2014:03:1793:1:0:NEW 30 Jul 2014) 


\section{Table 6(on next page)}

Measurements of lower molars

Table 6. Measurements of lower molars of Thylacinus potens and Th. cynocephalus. Data for UCMP 66206 are taken from Woodburne (1967). Data for Th. cynocephalus are mean values taken from Woodburne (1967) and Dawson (1982). Measurements are in mm. $L=$ mesiodistal length, $\mathrm{W} 1=$ width of the trigonid, $\mathrm{W} 2$ = width of the talonid. 


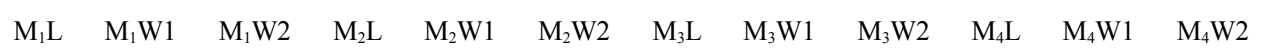

Th. potens

$\begin{array}{llllllllllll}\text { NTM P4326 } & 14.8 & 6.7 & 7.9 & 16.3 & (7.3) & 8.5 & 15.3 & 8.6 & 8.5 & 17.7 & 9.9\end{array}$

$\begin{array}{lllllllllllllll}\text { UCMP } 66206 & - & - & - & - & 13 & 6.8 & 6.8 & 14.5 & 8.3 & 6.2 & 15.4 & 8.8 & 5.1\end{array}$

Th. cynocephalus

Mean (Woodburne)

$\begin{array}{llllllll}12.0 & 5.7 & 6.2 & 14.0 & 6.9 & 6.8 & 16.0 & 7.8\end{array}$

4.3

Mean (Dawson) $\quad 9.6 \quad 4.4$

$12.0 \quad 5.7$

$14.1 \quad 6.9$

$15.7 \quad 7.6$ 


\title{
Table 7 (on next page) \\ Mass estimates for Thylacinus potens
}

\author{
Table 7. Mass estimates for two of the new specimens of Thylacinus potens. Regression \\ equations derived by Myers (2001) from his dasyuromorphian dataset. Abbreviations: 2UMW, \\ width of the second upper molar; UMRL, upper molar row length; LMRL, lower molar row \\ length.
}




\begin{tabular}{|c|c|c|c|c|c|}
\hline Specimen & Method & $\begin{array}{l}\text { Regression } \\
\text { Equation }\end{array}$ & $\begin{array}{l}\text { Measurement } \\
(\mathrm{mm})\end{array}$ & $\begin{array}{l}\text { Smearing } \\
\text { Estimate } \\
(\%) \\
\end{array}$ & $\begin{array}{l}\text { Mass } \\
\text { Estimate (kg) }\end{array}$ \\
\hline \multirow[t]{3}{*}{ NTM P4326 } & $\begin{array}{l}\text { Regression of } \\
\text { 2UMW }\end{array}$ & $\begin{array}{l}\log y=0.379+ \\
4.038(\log x)\end{array}$ & 14.7 & 3 & 120.6 \\
\hline & $\begin{array}{l}\text { Regression of } \\
\text { estimated } \\
\text { UMRL }\end{array}$ & $\begin{array}{l}\log y=-0.992+ \\
3.279(\log x)\end{array}$ & 51 & 1.2 & 40.9 \\
\hline & $\begin{array}{l}\text { Geometric } \\
\text { Similitude }\end{array}$ & & 43.2 & & 43.3 \\
\hline \multirow[t]{2}{*}{ NTM P4327 } & $\begin{array}{l}\text { Regression of } \\
\text { LMRL }\end{array}$ & $\begin{array}{l}\log y=-1.075+ \\
3.209(\log x)\end{array}$ & 63.3 & 3 & 56.1 \\
\hline & $\begin{array}{l}\text { Geometric } \\
\text { Similitude }\end{array}$ & & 63.3 & & 56.0 \\
\hline
\end{tabular}




\title{
Figure 1
}

\author{
Locality Map
}

Figure 1. Map of north-west corner of Alcoota Fossil Reserve showing the principal excavation sites of the Alcoota Local Fauna. 


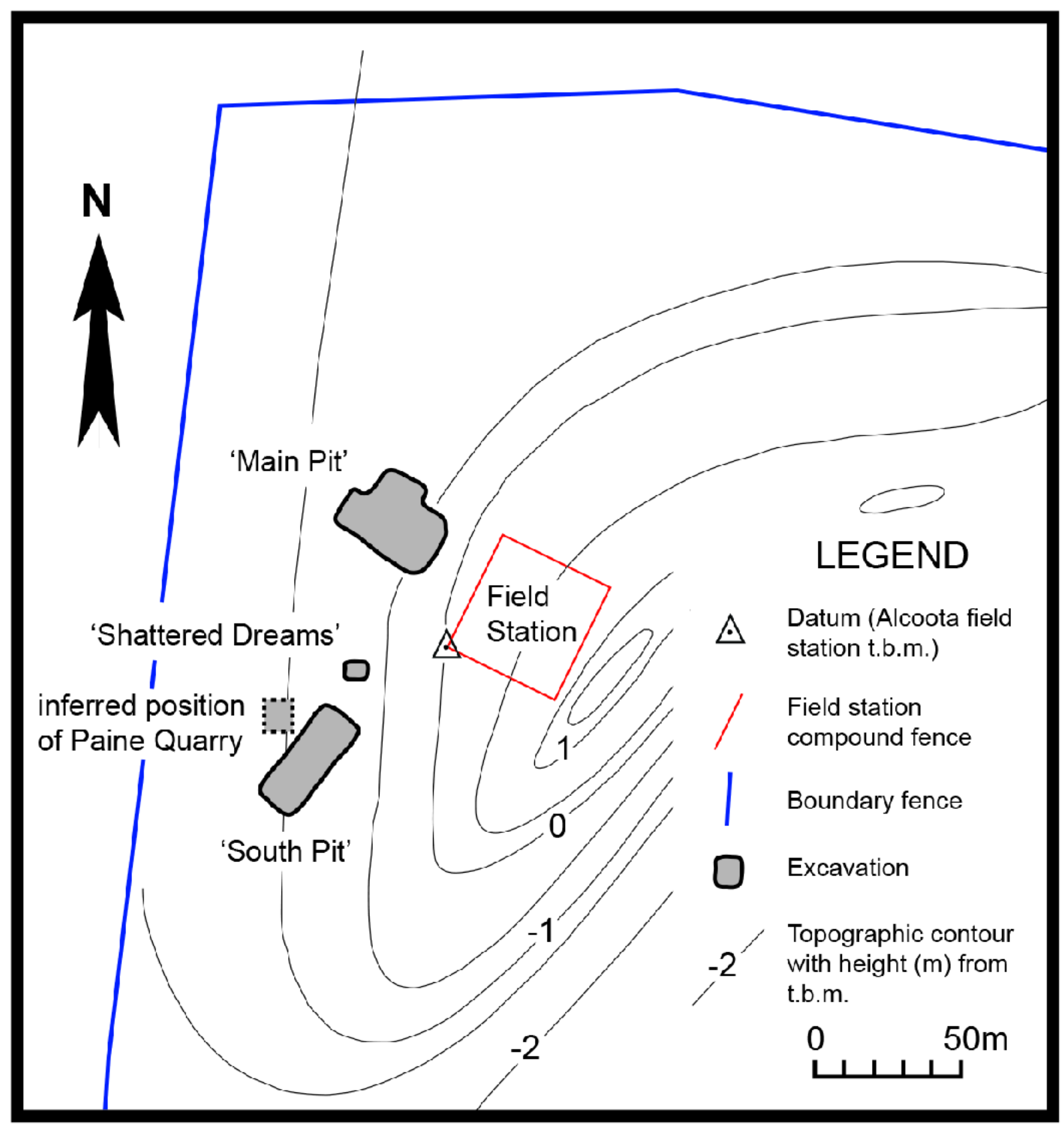




\section{Figure 2}

Whole maxilla

Figure 2. Thylacinus potens. NTM P4326, right maxilla. A, lateral view. B, ventral view. C, reconstruction of palate by mirror imaging the right side. Abbreviations: $\mathrm{Ca}$, canine alveolus; if, incisive foramen; iof, infraorbital foramen; M1-4, molars 1-4; P1-3, premolars 1-3; pf, palatine fenestra; sym, symphyseal surface. Scale bars $=50 \mathrm{~mm}$.

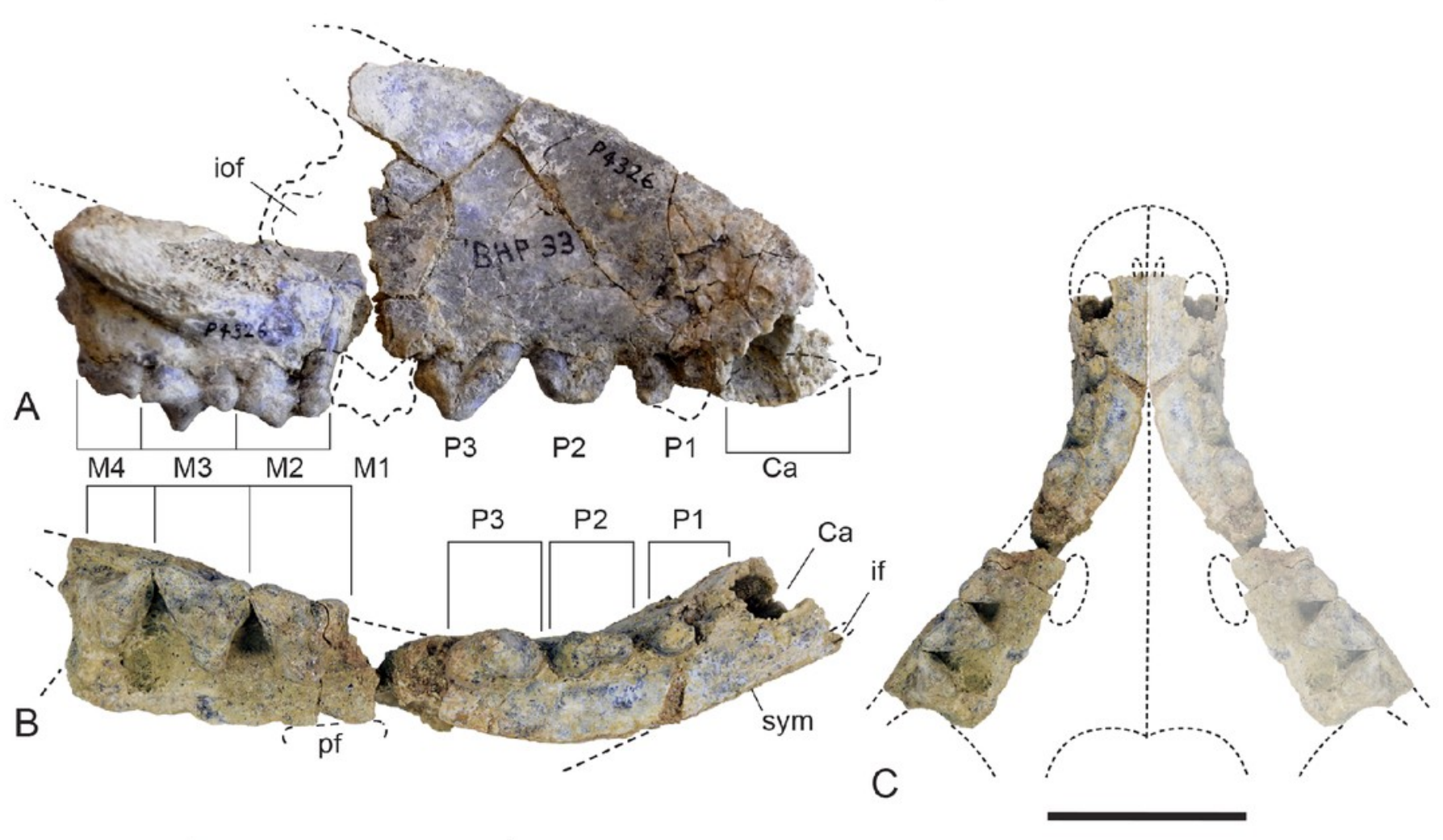




\section{Figure 3}

Comparison of Thylacinus maxillae.

Figure 3. Comparison of the maxilla of Thylacinus cynocephalus and Th. potens. A, left maxilla of Th. cynocephalus in lateral view. B, right maxilla (reversed for comparison) of $T h$. potens in lateral view. Both drawings scaled to the same maxillary length for comparison. A redrawn from Murray and Megirian (2006, Appendix 1, fig. 1), B based on NTM P4326. <!-$\diamond \mathrm{R}|\$|>->$ 


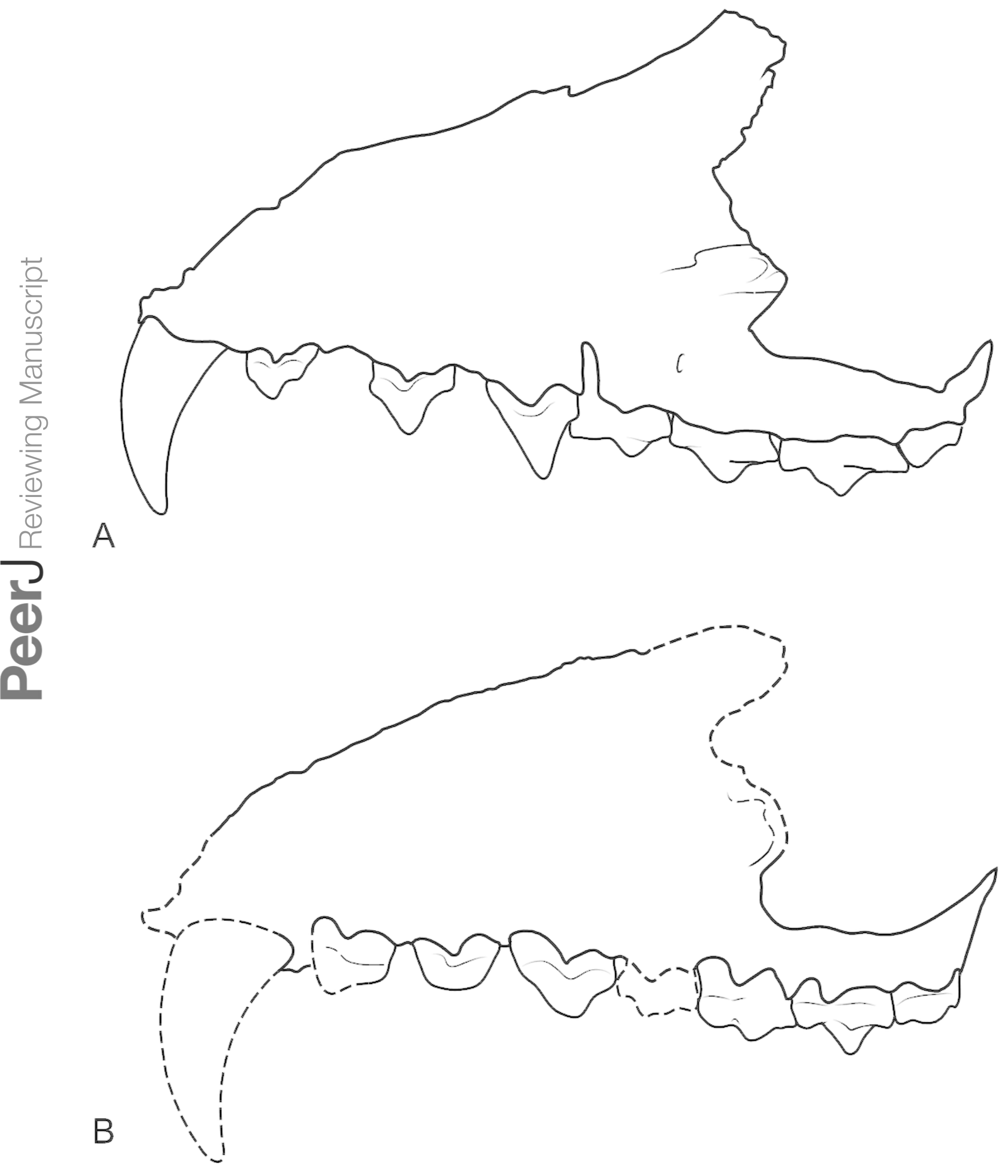




\section{Figure 4}

Photographs of anterior part of maxilla

Figure 4. Thylacinus potens. NTM P4326, detail of the anterior fragment of the right maxilla. A, lateral view. B, ventral view. C, medial view. Scale bar $=20 \mathrm{~mm}$. 


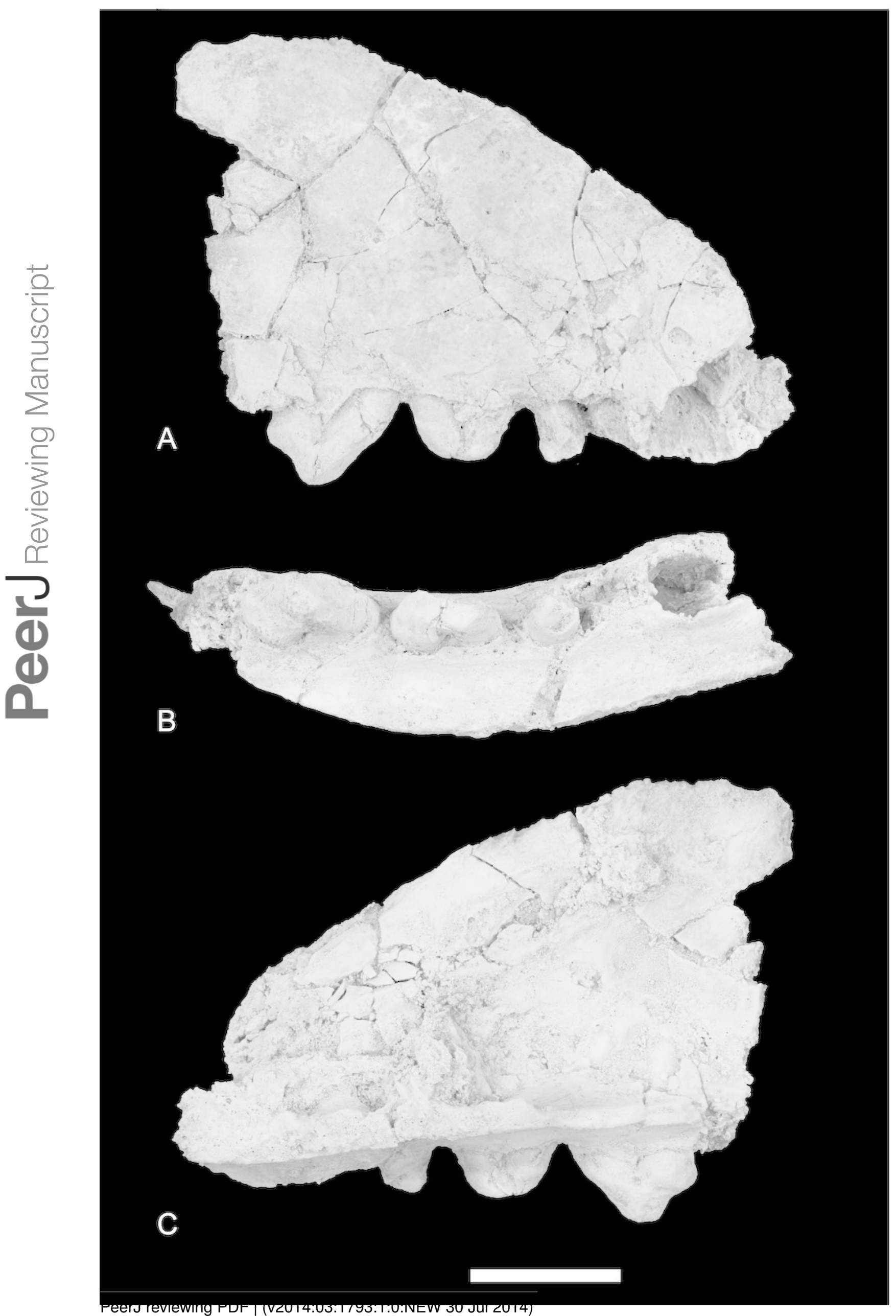




\section{Figure 5}

Drawings of anterior part of maxilla

Figure 5. Thylacinus potens. NTM P4326, anterior fragment of the right maxilla, interpretive drawings of the photographs in figure 4. A, lateral view. B, ventral view. C, medial view. Abbreviations: an, articulation surface for nasal; apm, articulation surface for premaxilla; ar, anterior root; ara, alveolus of the anterior root; arP1-3, anterior roots of premolars 1-3; bh, basal heel; Ca, canine alveolus; if, incisive foramen; $\mathrm{mp}$, palatal shelf of the maxilla; por, posterior root; porP1-3; distal root of premolars 1-3; pr, protocone; sym, symphyseal surface. Grey fill represent areas of adherent matrix, areas hatched with continuous horizontal lines represent broken bone and tooth surfaces. Scale bar $=30 \mathrm{~mm}$. 

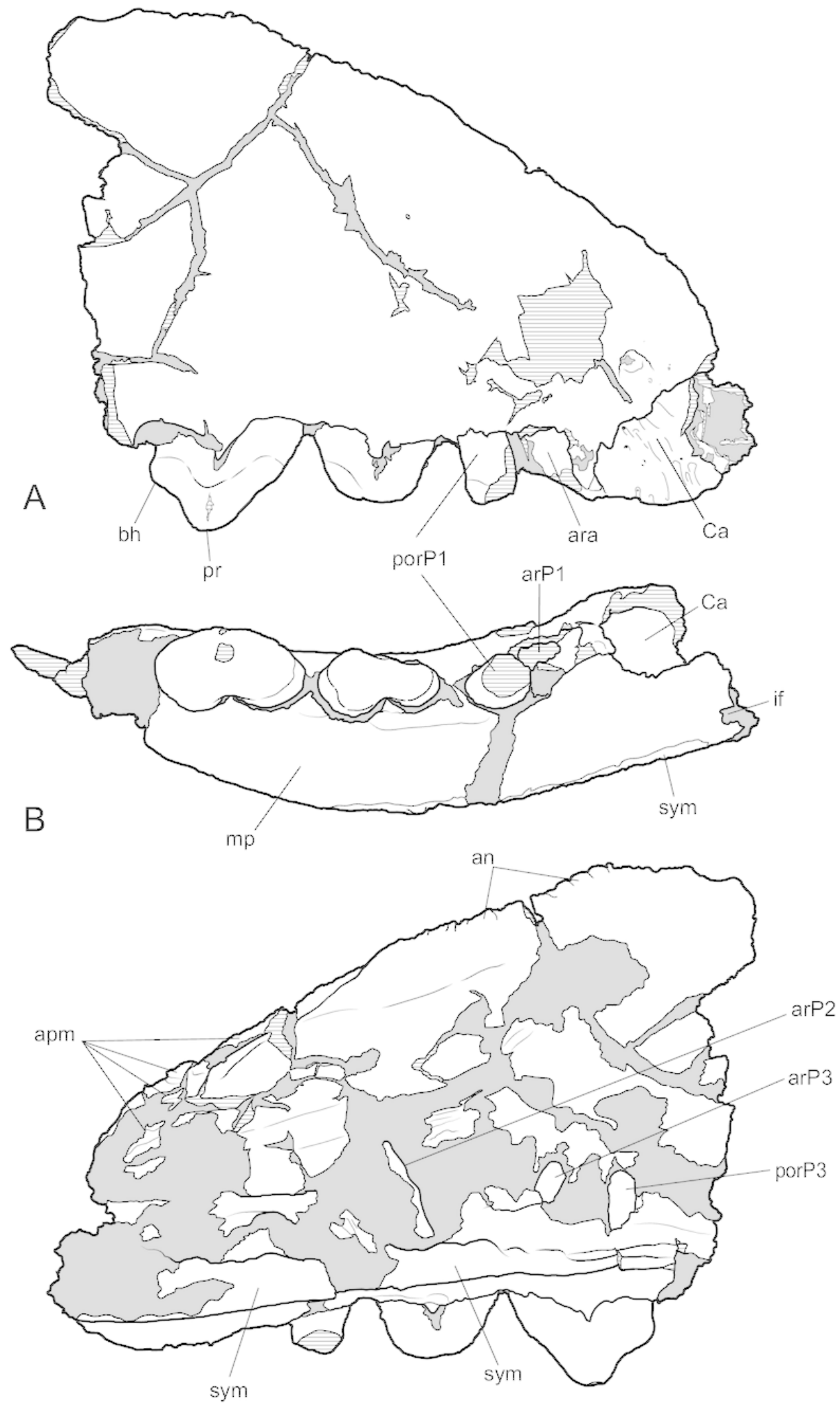

C

PeerJ reviewing PDF | (v2014:03:1793:1:0:NEW 30 Jul 2014) 


\section{Figure 6}

Posterior part of maxilla in lateral and medial views

Figure 6. Thylacinus potens. NTM P4326, detail of the posterior fragment of the right maxilla. A. lateral view. B, interpretive drawing of A. C, medial view. D, interpretive drawing of C. Abbreviations: aj, articulation surface for jugal; ap, articulation surface for palatine; ioc, infraorbital canal; me, metacone; mpf, margin of the palatal fenestra; ms, metastyle; pa, paracone; pr, protocone; ps, parastyle; sB, stylar cusp B; sD, stylar cusp D. Arrow indicates the level of the posterior margin of the infraorbital foramen. Grey fill represent areas of adherent matrix, areas hatched with continuous horizontal lines represent broken bone and tooth surfaces. Scale bar $=30 \mathrm{~mm}$. 


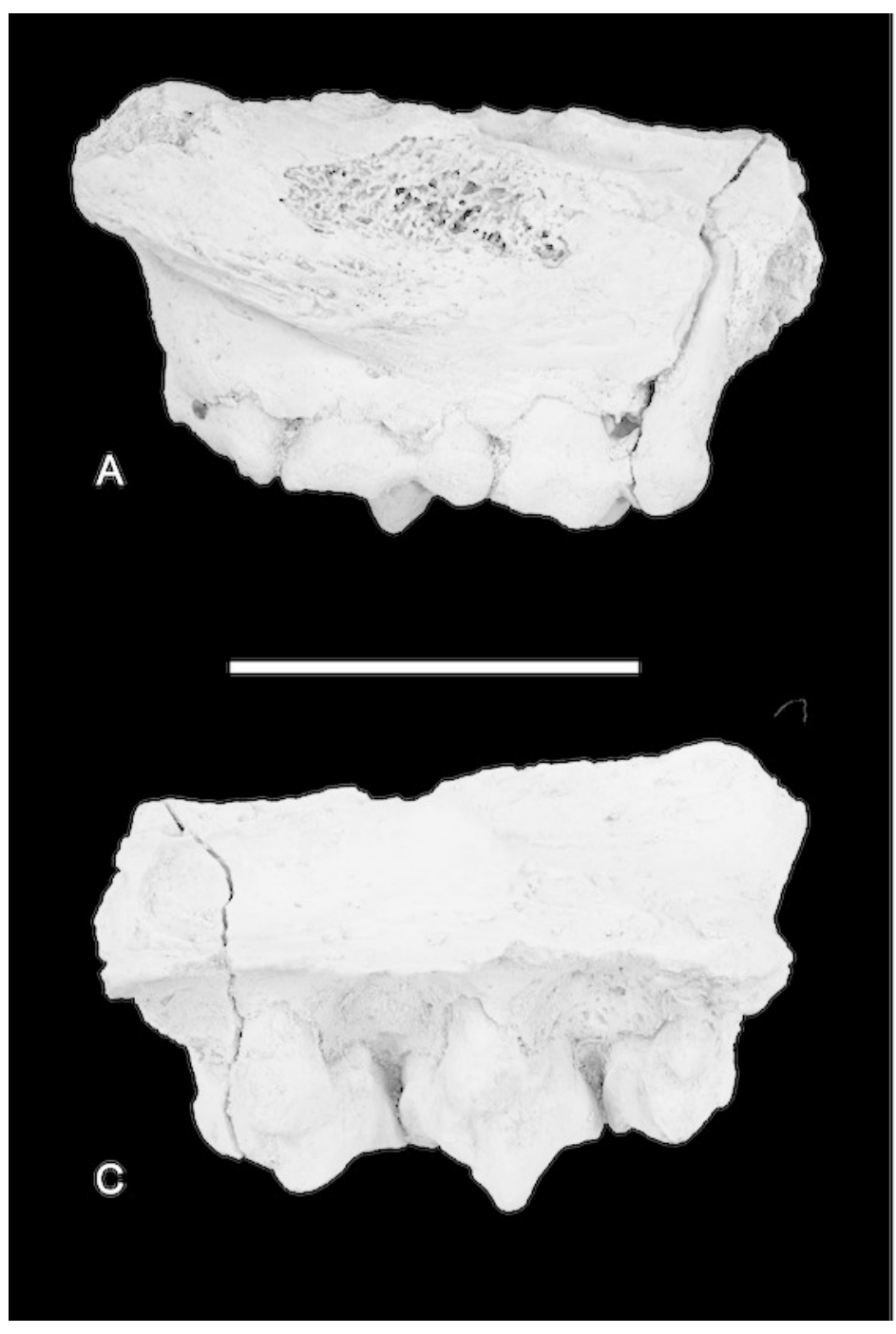

B

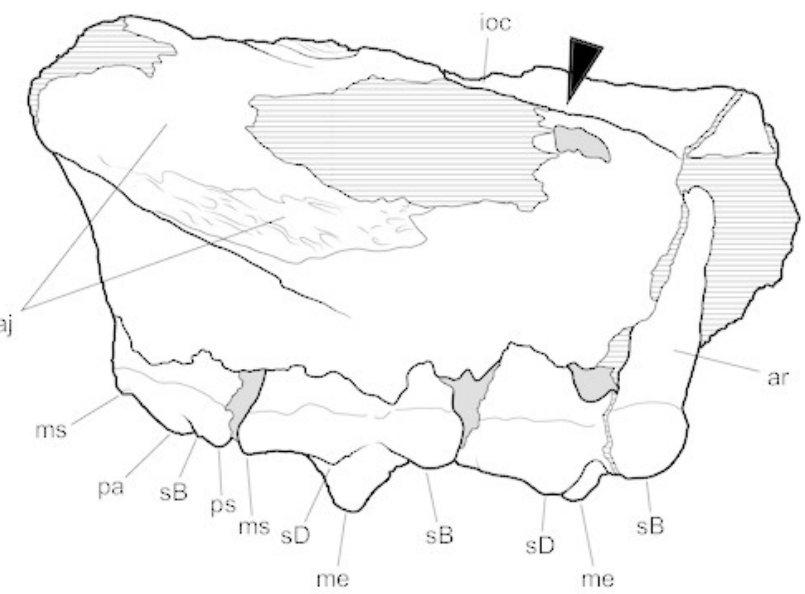

D

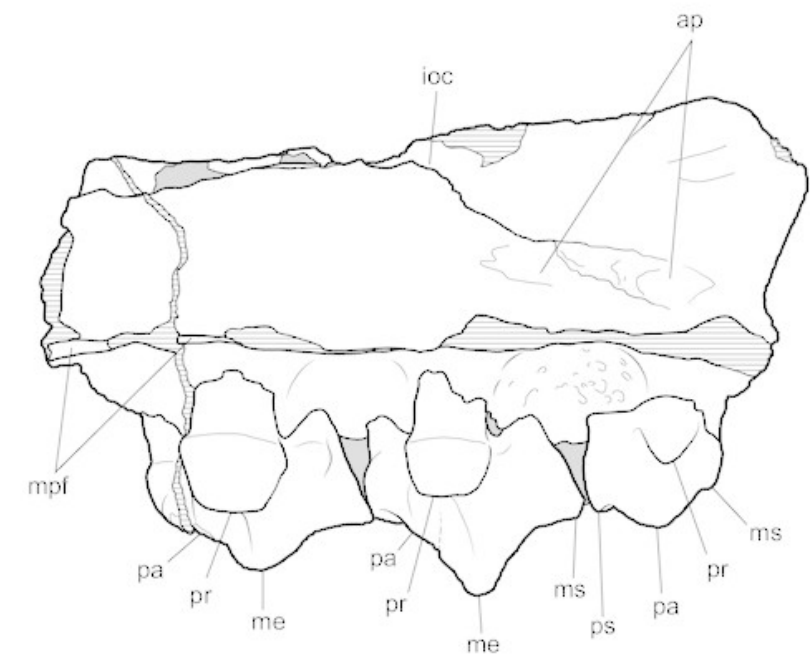




\section{Figure 7}

Photographs of posterior part of maxilla in ventral, anterior, dorsal and posterior views

Figure 7. Thylacinus potens. NTM P4326, detail of the posterior fragment of the right maxilla. A. ventral view. B, anterior view. C, dorsal view. D, posterior view. Scale bar $=30 \mathrm{~mm}$.

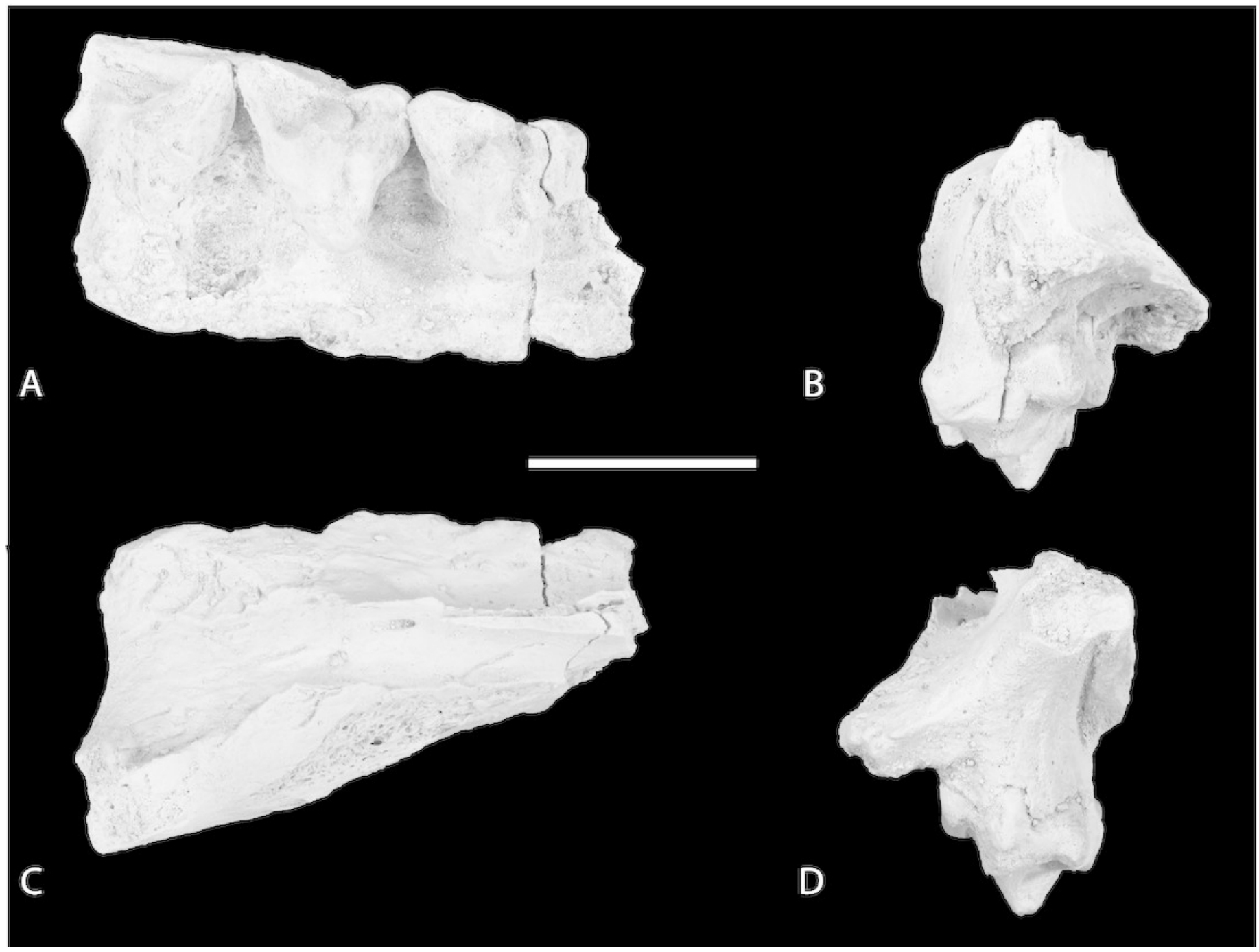




\section{Figure 8}

Drawings of posterior part of maxilla in ventral, anterior, dorsal and posterior views

Figure 8. Thylacinus potens. NTM P4326, posterior fragment of the right maxilla, interpretive drawings of the photographs in figure 7. A. ventral view. B, anterior view. C, dorsal view. D, posterior view. Abbreviations: aj, articulation surface for jugal; ap, articulation surface for palatine; ioc, infraorbital canal; me, metacone; mpf, margin of the palatal fenestra; ms, metastyle; pa, paracone; pr, protocone; ps, parastyle; sB, stylar cusp B; sD, stylar cusp D; vs, ventral sulcus. Grey fill represent areas of adherent matrix, areas hatched with continuous horizontal lines represent broken bone and tooth surfaces. Scale bar $=30 \mathrm{~mm}$. 

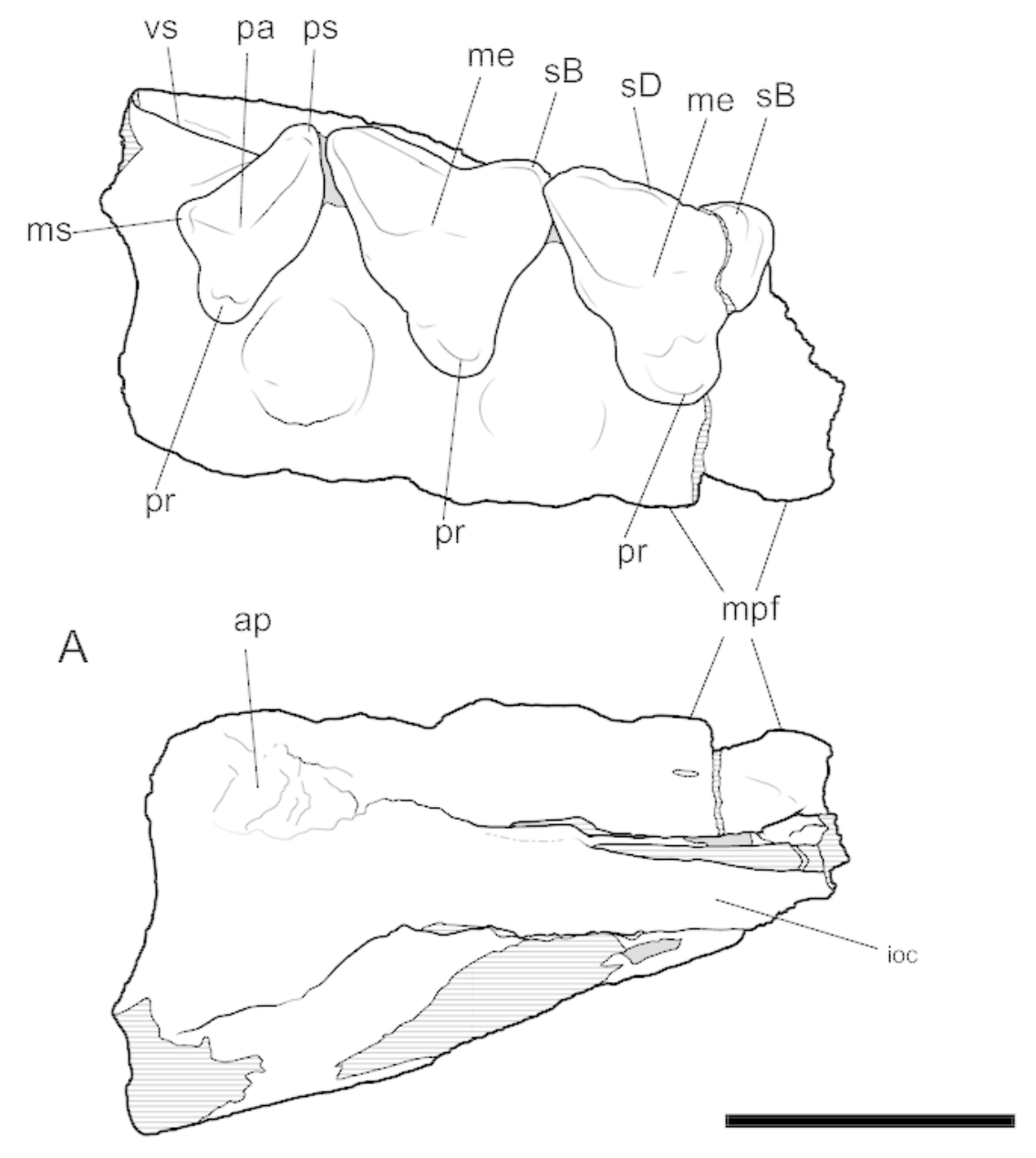

C
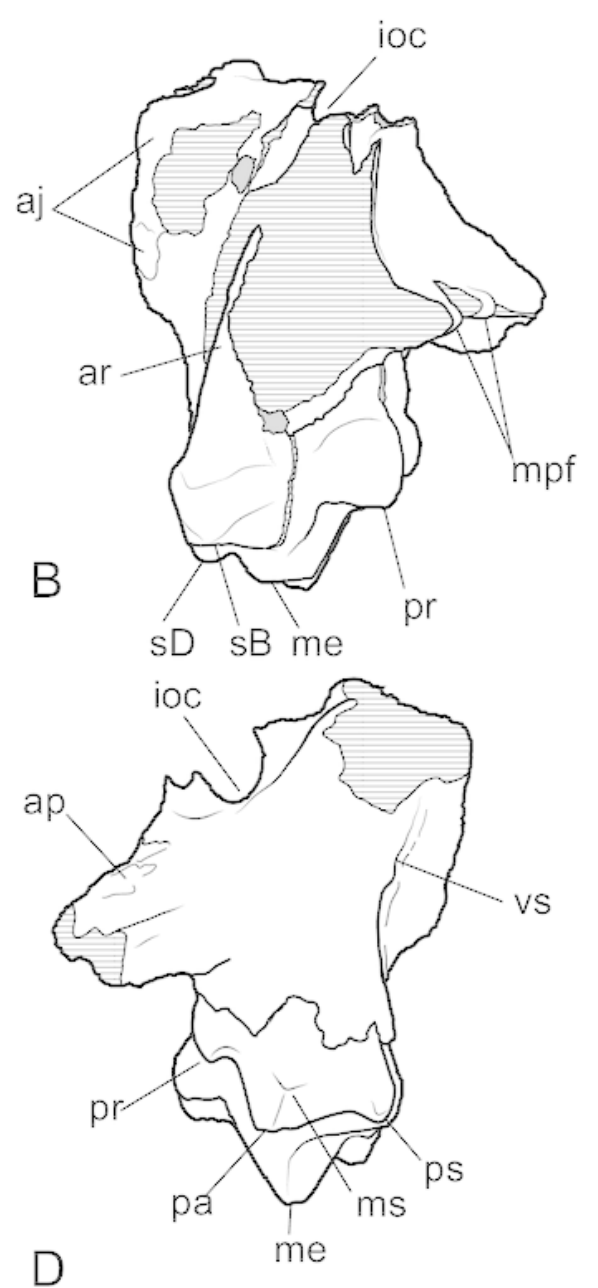


\section{Figure 9}

Close-up of upper molar dentition

Figure 9. Thylacinus potens. NTM P4326, detail of upper molar tooth row in occlusal view. A, photograph. B, interpretive drawing of A. Abbreviations: ef, ectoflexus; me, metacone; ms, metastyle; pa, paracone; pc, precingulum; pmc, postmetacrista; ppc, postparacrista; pprc, postprotocrista; pr, protocone; prpc, preparacrista; ps, parastyle; sB, stylar cup B; sD, stylar cusp D. Areas hatched with continuous horizontal lines represent broken tooth surfaces, areas hatched with discontinuous lines represent wear surfaces. Scale bar $=20 \mathrm{~mm}$. 


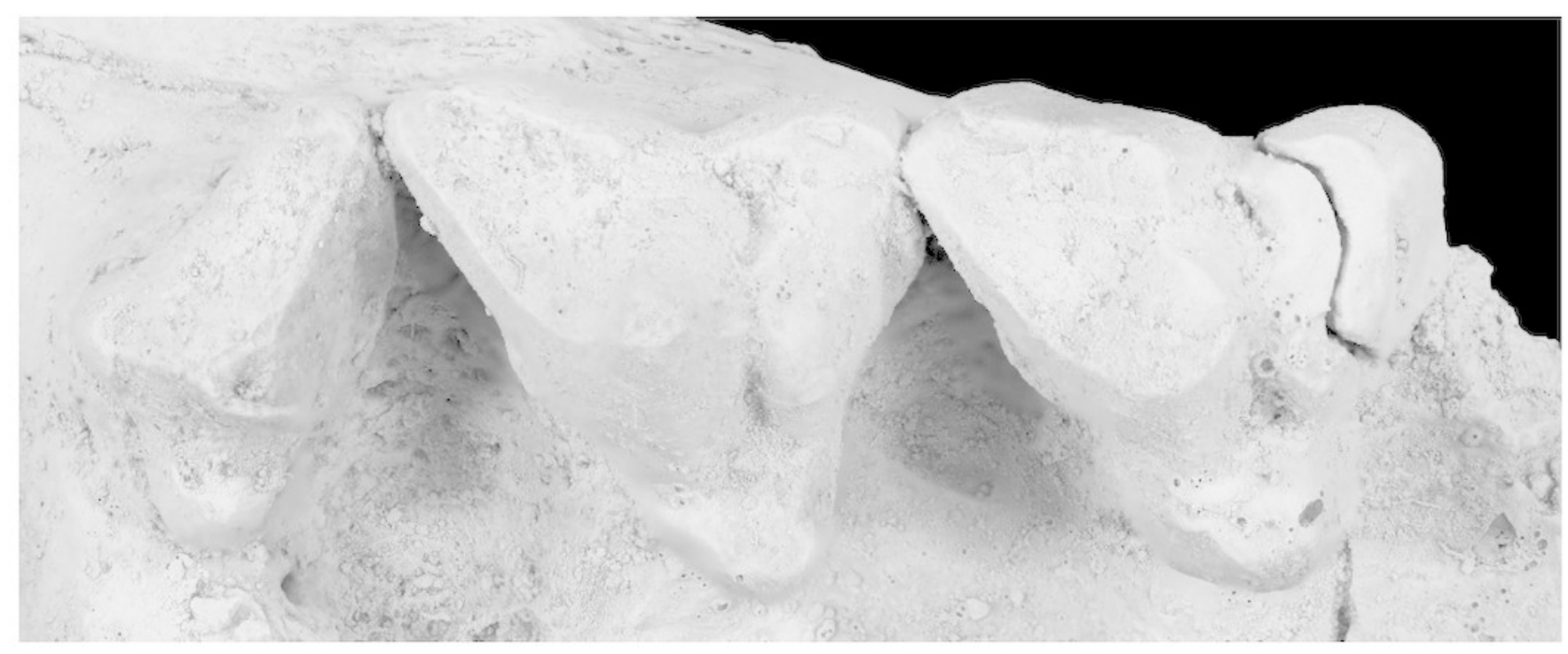

A

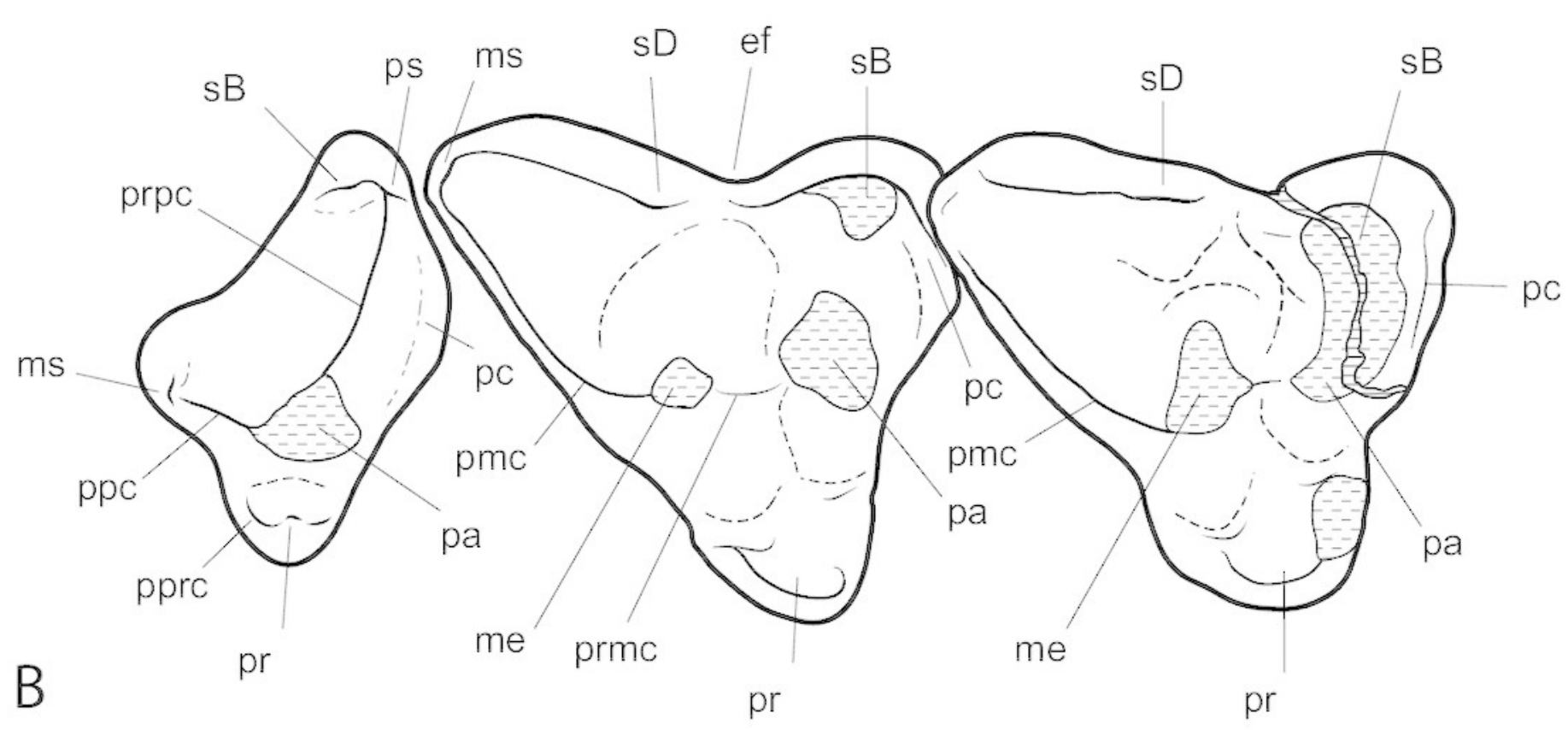




\section{Figure 10}

\section{Upper premolar}

Figure 10. Thylacinus potens. NTM P4332, isolated left $P^{3}$. A, buccal view. B, occlusal view. $C$, lingual view. $D$, interpretive drawing of $A$. $E$, interpretive drawing of $B$. F, interpretive drawing of C. Abbreviations: ar, anterior root; bh, basal heel; plcl, posterior lingual cuspule; por, posterior root; pr protocone. Grey fill represent areas of adherent matrix, areas hatched with continuous horizontal lines represent broken tooth surfaces, areas hatched with discontinuous lines represent wear surfaces. Scale bar $=10 \mathrm{~mm}$. 

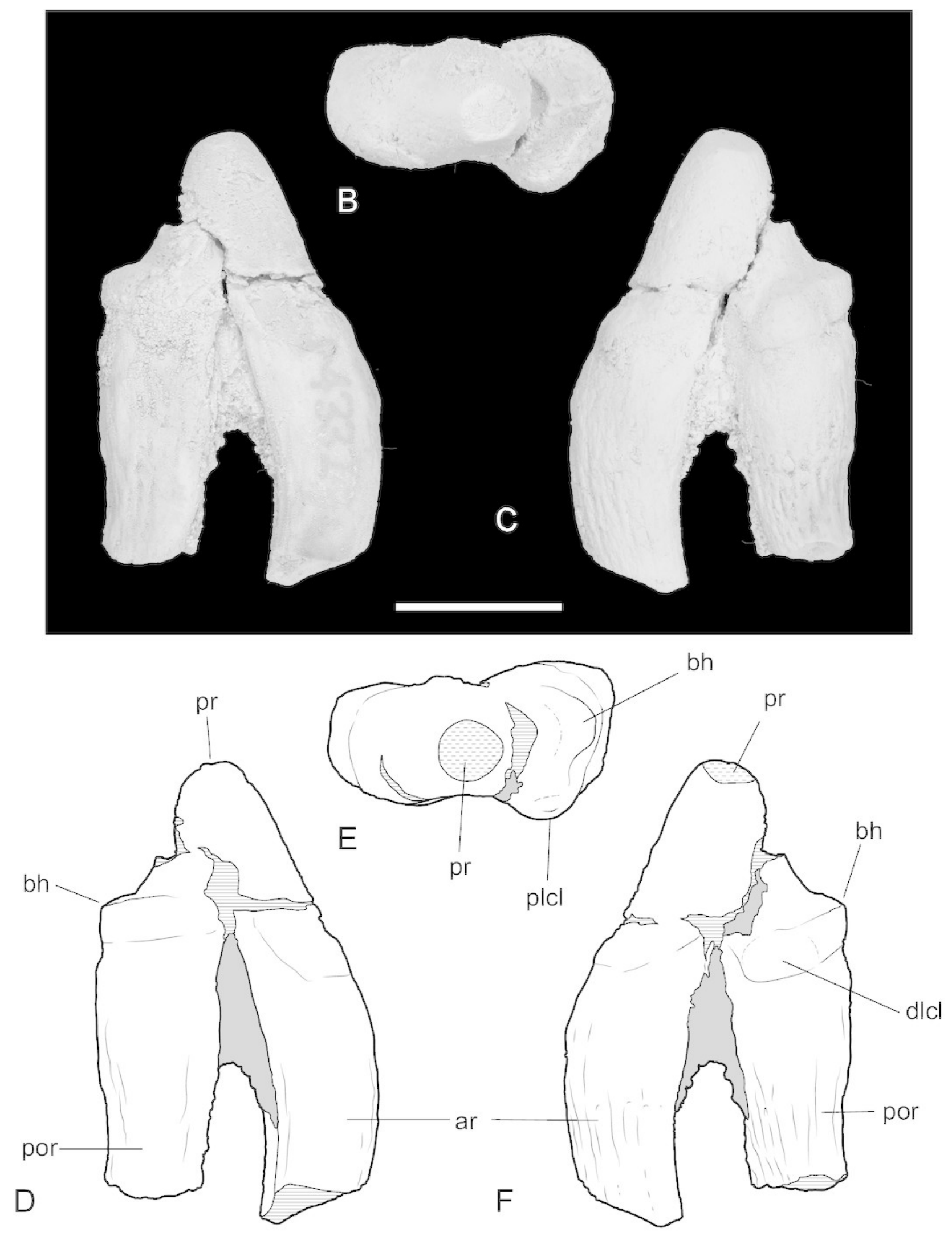


\section{Figure 11}

Heavily worn upper molar

Figure 11. Thylacinus potens. NTM P4379, heavily worn right $\mathrm{M}^{2}$ in a fragment of the right maxilla. A, photograph of occlusal view. B, photograph of buccal view. C, photograph of lingual view. D, interpretive drawing of A. $\mathbf{E}$, interpretive drawing of $B$. $\mathbf{F}$, interpretive drawing of C. Abbreviations: abr, anterior buccal root; ef, ectoflexus; Ir, lingual root; ms, metastyle; mx, maxilla fragments; pbr, posterior buccal root; pc, precingulum; pr, protocone; sB, stylar cusp B. Grey fill represent areas of adherent matrix, areas hatched with continuous horizontal lines represent broken tooth surfaces, areas hatched with discontinuous lines represent wear surfaces. Scale bar $=10 \mathrm{~mm}$. 


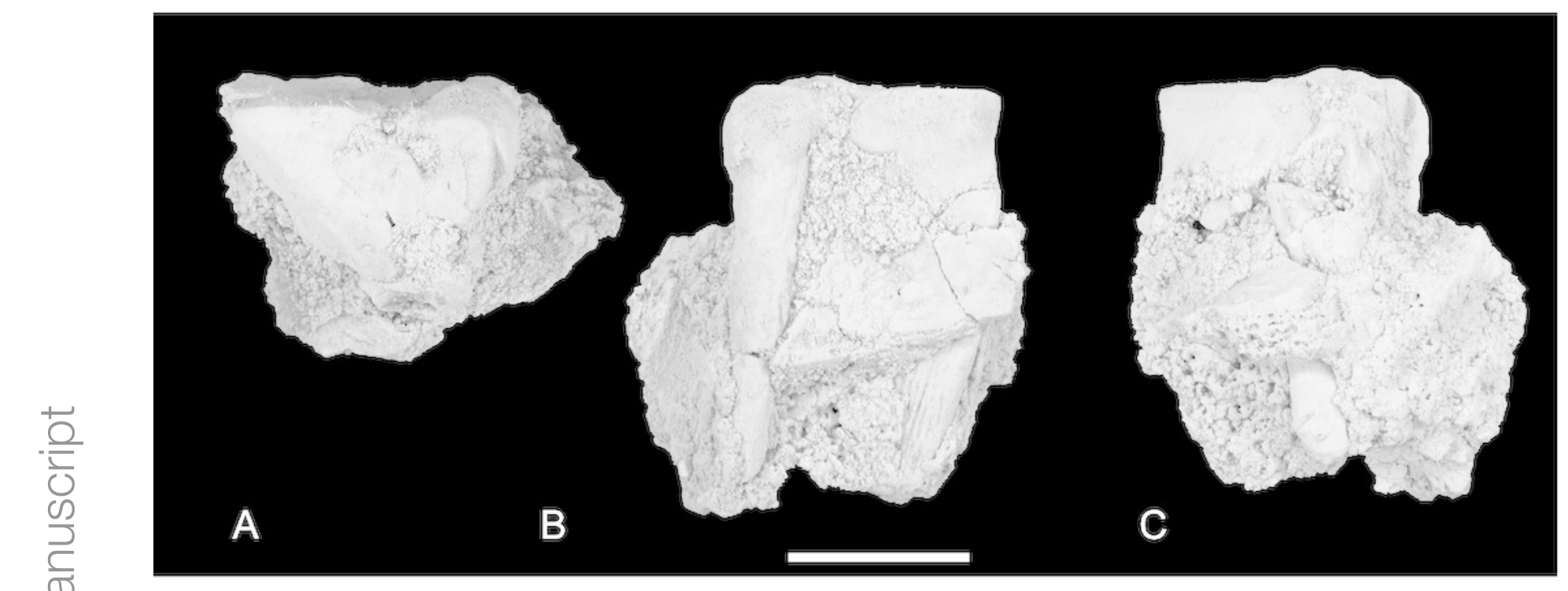

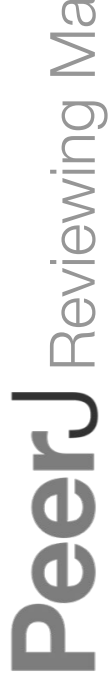

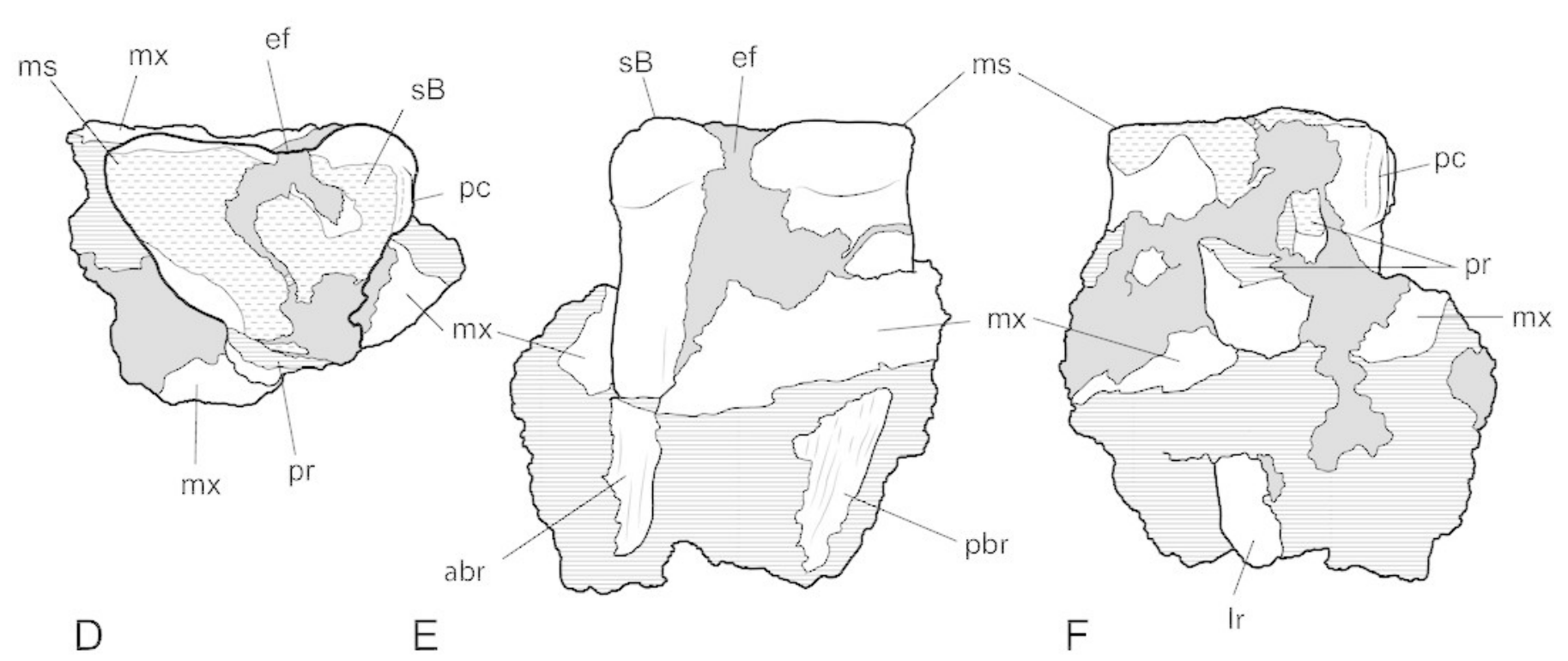




\section{Figure 12}

\section{Photographs of dentary}

Figure 12. Thylacinus potens. NTM P4327, photographs of horizontal ramus of left dentary. A, lateral view. B, occlusal view. C, medial view. Scale bar $=50 \mathrm{~mm}$. 


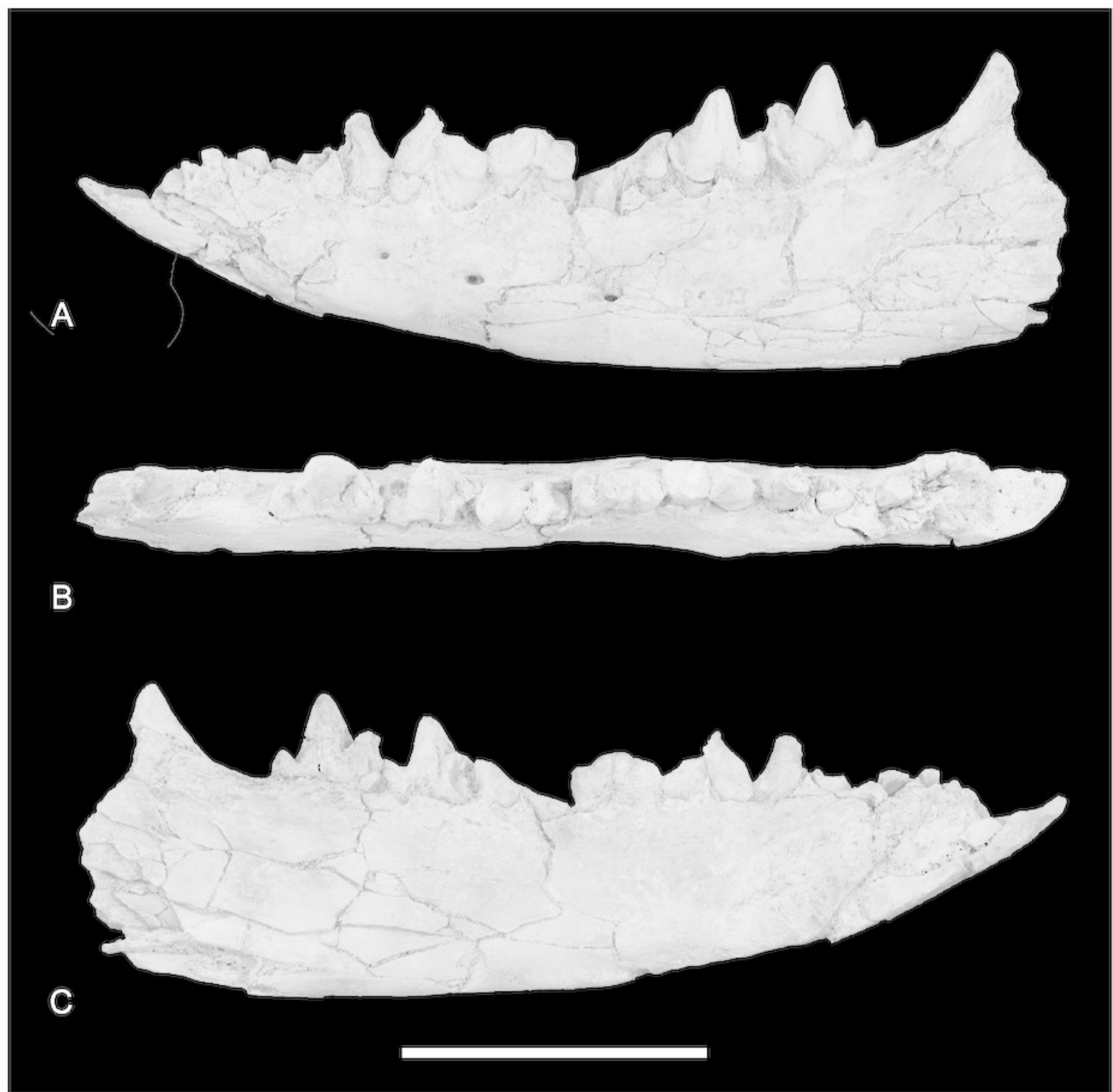




\section{Figure 13}

\section{Drawings of dentary}

Figure 13. Thylacinus potens. NTM P4327, interpretive drawings of figure 11. A, lateral view. B, occlusal view. C, medial view. Abbreviations: arp1, anterior root of first premolar; ca, lower canine alveolus; df, digastric fossa; m1-4, molars 1 to 4; mf, masseteric fossa; p1-3, premolars 1 to 3; pmf, posterior mental foramina; prp1, posterior root of first premolar; sym, symphyseal surface; vt, ventrolateral torus. Grey fill represent areas of adherent matrix, areas hatched with continuous horizontal lines represent broken bone and tooth surfaces, areas hatched with discontinuous lines represent wear surfaces. Scale bar $=50 \mathrm{~mm}$. 


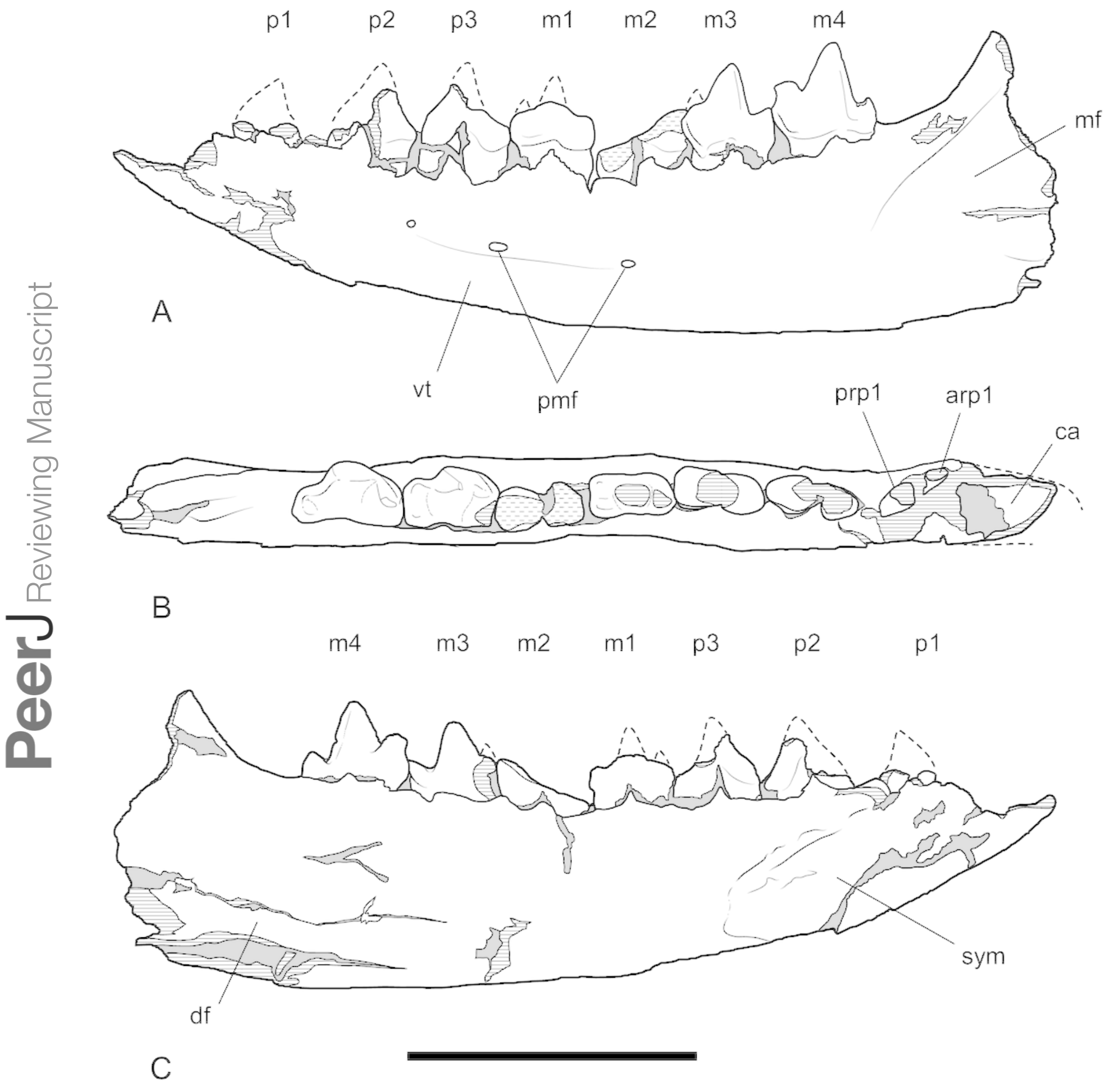




\section{Figure 14}

Closeups of lower molars in occlusal view

Figure 14. Thylacinus potens. NTM P4327, detail of lower molar tooth row in occlusal view. A, posterior molars. B, first molar. C, interpretive drawing of A. D, interpretive drawing of B. Abbreviations: cdo, cristid obliqua; cn, carnassial notch; ed, entoconid; hd, hypoconid; pad, paraconid; pcd, postcristid; pcid, precingulid; ppcd, postparacristid; prd, protoconid; prpcd, preprotocristid. Grey fill represent areas of adherent matrix, areas hatched with continuous horizontal lines represent broken tooth surfaces, areas that are hatched with discontinuous lines represent wear surfaces. Scale bar=20 mm. l--End S D @-->
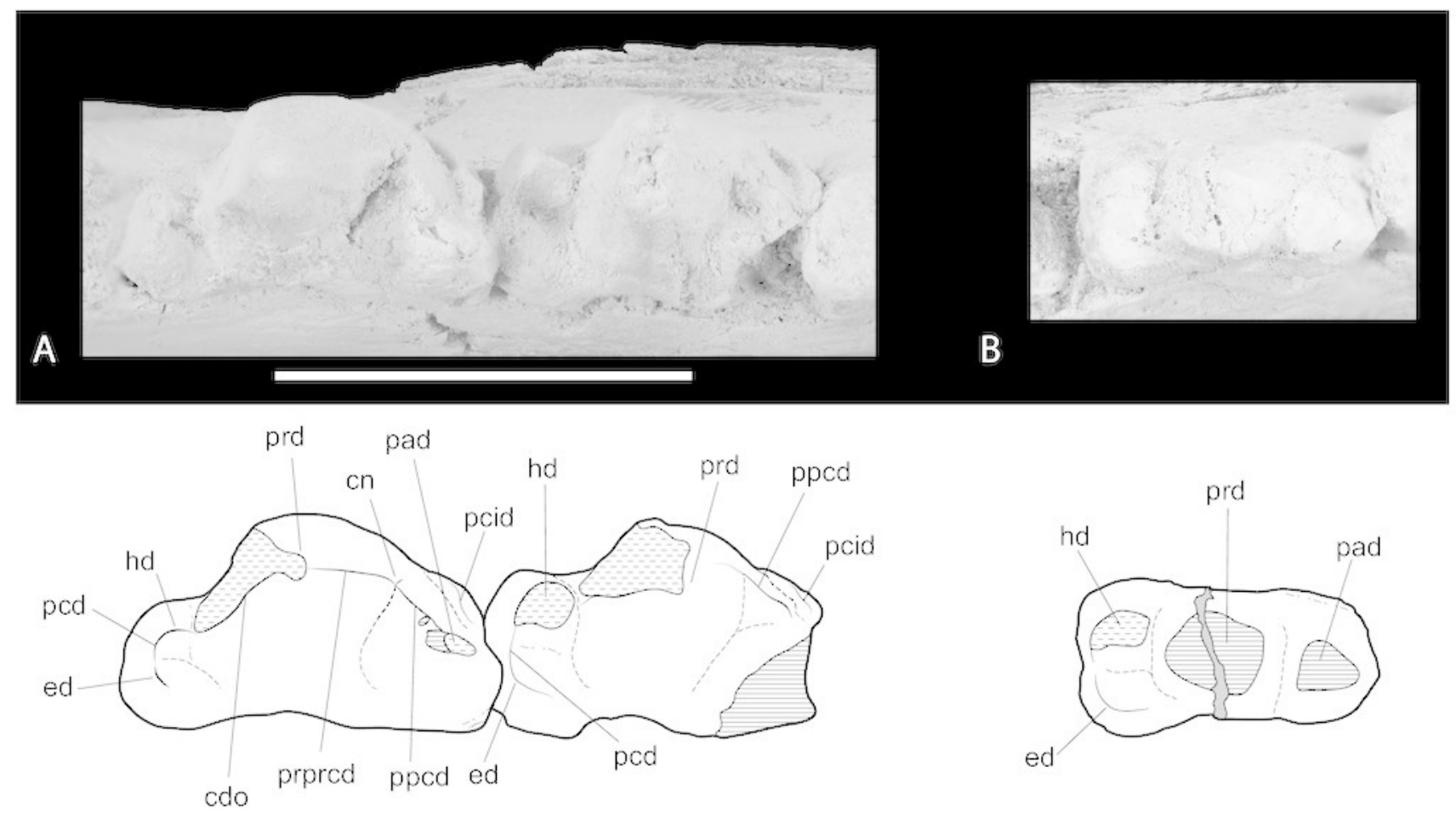

C

m4

$\mathrm{m} 3$ 


\section{Figure 15}

Closeups of lower molars in buccal view

Figure 15. Thylacinus potens. NTM P4327, detail of lower molar tooth row in buccal view. Abbreviations: cdo, cristid obliqua; cn, carnassial notch; ed, entoconid; hd, hypoconid; pad, paraconid; pcd, postcristid; pcid, precingulid; prd, protoconid; prpcd, preprotocristid. Grey fill represent areas of adherent matrix, areas hatched with continuous horizontal lines represent broken tooth surfaces, areas that are hatched with discontinuous lines represent wear surfaces. Scale bar $=20 \mathrm{~mm}$. 


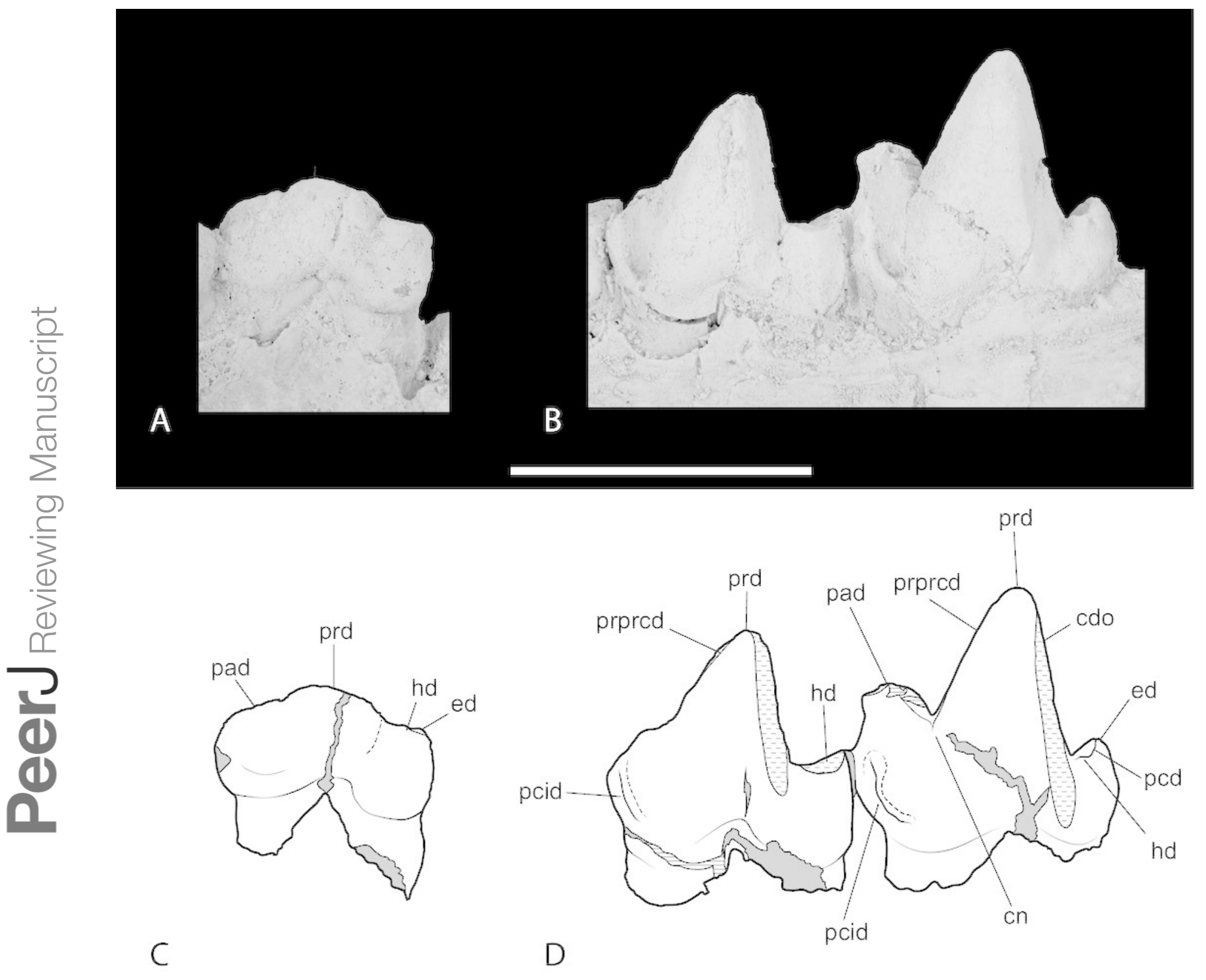




\section{Figure 17}

Results of cladistic analysis of thylacinid relationships

Figure 17. Consensus trees of two most-parsimonious-trees (tree length $=88$ steps) resulting from a cladistic analysis of 13 thylacinid taxa with Dasyuridae set as the user-defined outgroup. A, strict consensus with bootstrap support values for clades with support values $>50 \%$. B, fully resolved reduced cladistic consensus obtained after a posteriori pruning of Maximucinus muirheadae. Letters at nodes correspond to those in the tree description in Appendix 2. 


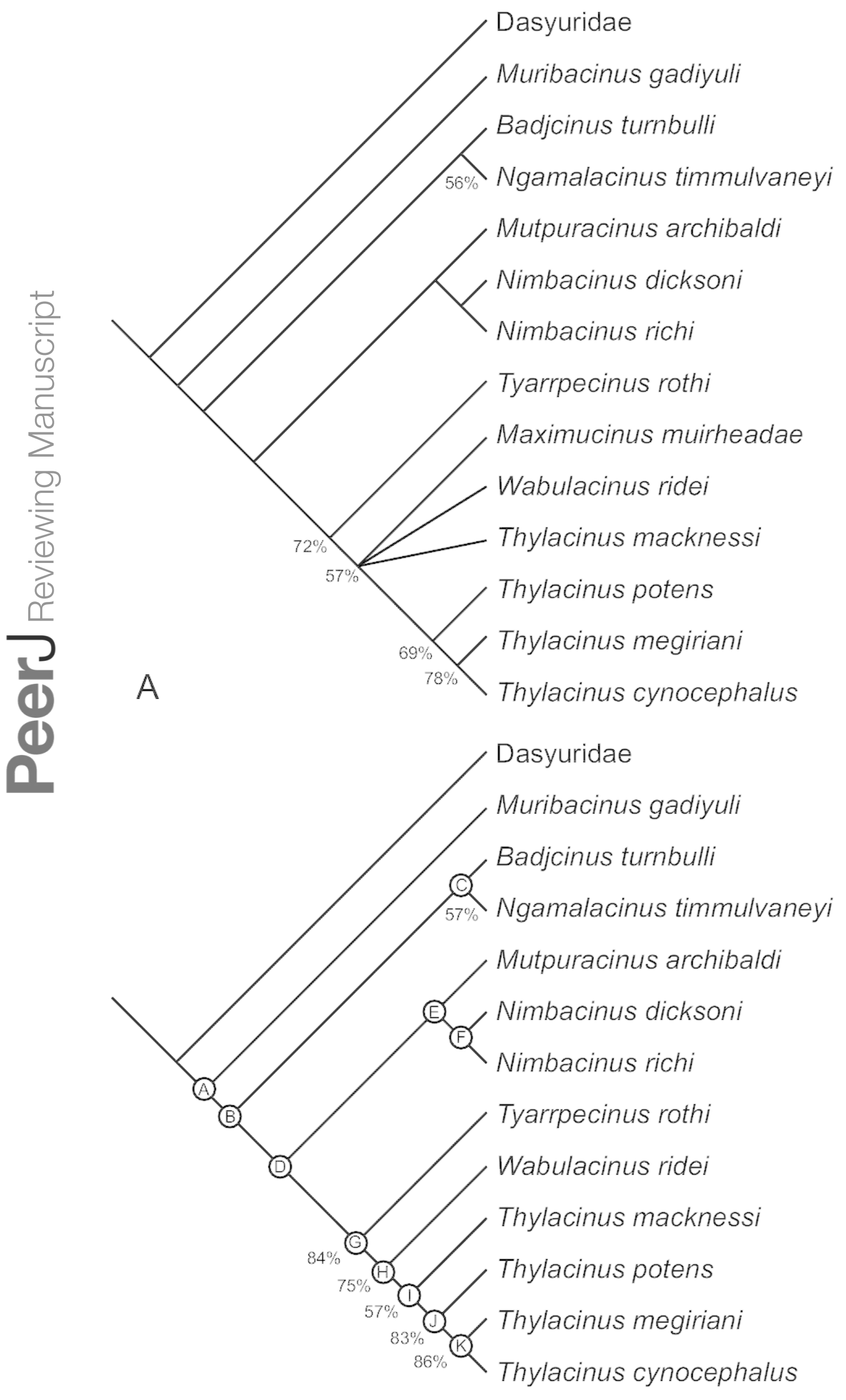

PeerJ reviewing PDF | (v2014:03:1793:1:0:NEW 30 Jul 2014) 